NBER WORKING PAPER SERIES

\title{
AIDS TREATMENT AND INTRAHOUSEHOLD RESOURCE ALLOCATIONS: CHILDREN'S NUTRITION AND SCHOOLING IN KENYA
}

\author{
Joshua S. Graff Zivin \\ Harsha Thirumurthy \\ Markus Goldstein \\ Working Paper 12689 \\ http://www.nber.org/papers/w12689
}

\author{
NATIONAL BUREAU OF ECONOMIC RESEARCH \\ 1050 Massachusetts Avenue \\ Cambridge, MA 02138 \\ November 2006
}

This project would not have been possible without the support of the Academic Model for Prevention and Treatment of HIV/AIDS (AMPATH) and members of the IU-Kenya partnership. We are grateful to Michael Boozer, David Cutler, T. Paul Schultz, Christopher Udry, and seminar participants at the NBER Health Care Program Meeting, the Northeast Universities Development Consortium Conference, the University of Pittsburgh, and Yale University for comments and suggestions. Many individuals contributed to the implementation of the household survey under the direction of the authors and Mabel Nangami. Giovanna d'Adda assisted in managing the second round of the survey and the data collection was facilitated by the field supervision of Irene Muhunzu. We also acknowledge the tremendous contributions of Andrew Anyembe, Caroline Amuyunzu, Jayne Chaina, Norbert Ketter, James Mungai, June Ochanda, and Jacklyne Tetee for administering questionnaires; and Chelimo Cherono, David Marende, Maurice Mungai, Florence Oduor, and Martha Simiyu for computer entry of questionnaires. Financial support for this project was received from the Economic and Social Research Council (UK), Pfizer, Inc., The World Bank, Yale University's Center for Interdisciplinary Research on AIDS (CIRA) through a grant from the National Institute of Mental Health to Michael Merson, M.D. (No. P30 MH 62294), the Social Science Research Council, and the Calderone Program at Columbia University. The views expressed here do not necessarily reflect those of the World Bank or its member countries. All errors and opinions are our own. The views expressed herein are those of the author(s) and do not necessarily reflect the views of the National Bureau of Economic Research.

(C) 2006 by Joshua S. Graff Zivin, Harsha Thirumurthy, and Markus Goldstein. All rights reserved. Short sections of text, not to exceed two paragraphs, may be quoted without explicit permission provided that full credit, including (C) notice, is given to the source. 
AIDS Treatment and Intrahousehold Resource Allocations: Children's Nutrition and Schooling in Kenya

Joshua S. Graff Zivin, Harsha Thirumurthy, and Markus Goldstein

NBER Working Paper No. 12689

November 2006

JEL No. I1,I2,O12,O15

\begin{abstract}
The provision of life-saving antiretroviral (ARV) treatment has emerged as a key component of the welfare of children in the households of treated persons. We estimate the impact of ARV treatment adult household member. For boys in treatment households, these increases closely follow their reduced provide evidence on how intrahousehold resource allocation is altered in response to significant health is likely to generate significant long-run macroeconomic benefits.

Joshua S. Graff Zivin

Department of Health Policy and Management

Columbia University

600 West 168th Street, Room 608

New York, NY 10032

and NBER

jz126@columbia.edu

Harsha Thirumurthy

1776 Massachusetts Ave, NW

Washington DC 20036

HThirumurthy@cgdev.org

Markus Goldstein

Poverty Reduction Group

MSN MC4-415

1818 H Street, NW

Washington DC 20433

mgoldstein@worldbank.org
\end{abstract} global response to HIV/AIDS, but very little is known about the impact of this intervention on the on children's schooling and nutrition outcomes using longitudinal household survey data collected in collaboration with a treatment program in western Kenya. We find that children's weekly hours of school attendance increase by over 20 percent within six months after treatment is initiated for the market labor supply. Similarly, young children's short-term nutritional status-as measured by their weight-for-height Z-score-also improves dramatically. We argue that these treatment effects will be considerably larger when compared to the counterfactual scenario of no ARV treatment. The results improvements. Since the improvements in children's schooling and nutrition at these critical early ages will affect their socio-economic outcomes in adulthood, the widespread provision of ARV treatment 


\section{Introduction}

Health and education are widely recognized as two important dimensions of human capital, offering high economic returns and capable of improving prospects for economic development (among others, see Schultz and Tansel, 1997; Schultz, 1999; Strauss and Thomas, 1998; Duflo, 2001 for evidence from developing countries). The threat posed to children's human capital is among the most negative and far-reaching consequence of AIDS-related morbidity and mortality in sub-Saharan Africa. ${ }^{1}$ While the provision of life-saving antiretroviral (ARV) treatment has emerged as a central part of the medical and policy response to HIV/AIDS, ${ }^{2}$ very little empirical research has investigated the impacts of this important intervention on children's welfare. The long-term macroeconomic consequences of HIV/AIDS and treatment in afflicted countries depends critically on our understanding of these intergenerational effects (Bell, Gersbach, and Devarajan, 2003; Young, 2005). Such information also lies at the heart of the debate about the merits of prevention versus treatment policies (Canning, 2006). This paper is, to our knowledge, the first to estimate the impact of ARV treatment for adults on the welfare of children living in their households.

Children living in households with HIV-infected adults are likely to be affected by both the morbidity and mortality that is associated with AIDS. First, since untreated AIDS is fatal, many children will become orphaned. A growing empirical literature shows that orphaned children in Africa suffer major setbacks in their schooling in the years before and after they lose their parents (Evans and Miguel, 2005; Yamano and Jayne, 2005; Case and Ardington, 2005). There is also evidence that the long-run health of orphans is negatively affected (Beegle, De Weerdt, and Dercon, 2005). Second, the morbidity associated with AIDS may lead to reallocations of time and resources within the household. These reallocations can be an important consumption-smoothing mechanism in low-income settings with imperfect credit and insurance markets, and several studies have documented their use in response to other health and income shocks (see, for example, Pitt and Rosenzweig, 1990; Strauss and Thomas, 1995; Kochar, 1995; and Jacoby and Skoufias, 1997). In the case of AIDS, the health and income

\footnotetext{
${ }^{1}$ In sub-Saharan Africa, roughly 12 million children under the age of 18 have lost one or both parents due to AIDS (UNAIDS, 2005).

2 The World Health Organization reports that as of December 2005, 810,000 HIV-positive individuals were estimated to be receiving ARV treatment in sub-Saharan Africa (WHO, 2006). However, this number represents only 17 percent of the 4.7 million HIV-positive individuals who currently need treatment.
} 
'shock' is both large and, absent treatment, permanent, implying that children's time allocation patterns could be altered to a greater extent than they would be in response to transitory shocks.

Adults in poor health typically require considerable amounts of care from household members, including children. The diminished productivity of sick adults will have income and substitution effects that hasten the participation of children in income-generating activities. The additional time spent by children on either of these activities is likely to come, at least partly, at the expense of schooling. Moreover, since the marginal productivity of children who expand their labor force participation in response to family illness is less than that of a healthy adult, family income will fall. ${ }^{3}$ This reduction in income may lead to reduced household consumption, thereby compounding the education effects and increasing the risk of malnourishment by lessening children's access to food. ${ }^{4}$ ARV treatment, which dramatically improves patient health and market labor supply (Thirumurthy, Graff Zivin, and Goldstein, 2005), has the potential to reverse these impacts of AIDS-related morbidity and mortality.

As such, this paper should also be viewed as a significant contribution to the more general economic literature on intrahousehold resource allocation decisions, shedding light on how households respond to the negative consequences of disease as well as the positive ones due to treatment. There is a significant literature in development economics on how households manage resources to cope with permanent and temporary shocks. The literature focuses on mechanisms such as informal insurance, credit, and intrahousehold reallocation of consumption and production. ${ }^{5}$ In this paper, we provide some evidence of the significant effects of the shock of AIDS on household education and consumption decisions. The introduction of treatment, in turn, allows us to examine the sensitivity of these adjustments to the patient's recovery, providing an opportunity to assess the extent to which these coping strategies result in irreversible changes. Together, they deepen our understanding of intrahousehold dynamics and human capital formation in the developing world.

\footnotetext{
${ }^{3}$ A large theoretical and empirical literature examines the role of income and substitution effects in individual time allocation decisions (beginning with Becker, 1965) and family labor supply (beginning with Ashenfelter and Heckman, 1974).

${ }^{4}$ Recent research has also established strong linkages between the nutrition of children and their current as well as future schooling outcomes (Alderman, Behrman, Lavy, and Menon, 2001; Glewwe, Jacoby, and King, 2001; Glewwe and King, 2001; Miguel and Kremer, 2004).

${ }^{5}$ See for example Paxson, 1992; Udry, 1994; Townsend, 1994; Kochar, 1999; Duflo, 2003; and Case and Deaton 1998.
} 
The empirical work in this paper is based on a household survey we conducted in collaboration with an ARV treatment program in western Kenya. Over the course of one year, longitudinal socio-economic data were collected from HIV-positive adult patients who had AIDS and received free ARV treatment. The survey data include information on the schooling and nutritional outcomes of children residing in the patients' households. We examine changes over time in these outcomes, focusing on the school enrollment and school hours attended of children between the ages of 8-18 years and the anthropometric status of children under the age of 5 years. The effect of ARV therapy on children's outcomes is identified by examining outcomes at several points in time, both before and after adults in the children's households receive treatment. Using data collected simultaneously from a large random sample of non-patient households in the survey area, we control for time-varying factors that could bias the estimates. The approach is tantamount to a difference-in-difference estimation strategy in which the treatment group consists of children in households of ARV recipients and the comparison group consists of children in the survey area. ${ }^{6}$ The longitudinal aspect of the survey data and the random sample of households in the community are critical for identifying the effect of treatment. As we discuss below, our identification strategy is also strengthened by variation in the length of time that adult patients had been receiving treatment prior to the start of the survey.

The results in this paper indicate that treating adult AIDS patients with ARV treatment results in substantial improvements in the welfare of children living with the patients. Our primary result indicates that there is a significant increase in the children's weekly hours of school attendance. These increases generally occur within six months after treatment is initiated for adult patients, and they are experienced by boys and girls living with the patients. Our main results imply that weekly school hours attended rise by over 20 percent during this period, with boys experiencing an even larger rise of 30 percent. After nine months of treatment, the increases in school attendance are maintained with no significant drop off over the time period of our study. Moreover, we find that for boys in particular, the increase in hours of attendance is almost exactly equal to the treatment-driven decrease in their hours of market labor supply.

The treatment effect is considerably larger when we compare children in treatment households to orphans in the random sample. This suggests that pre- and post-treatment

\footnotetext{
${ }^{6}$ Given the clinical effectiveness of ARV therapy, the construction of a randomly chosen control group of children living with HIV-positive adults who are medically qualified for ARV treatment but do not receive it is ethically infeasible.
} 
comparisons that do not consider the "no treatment" or counterfactual scenario of children becoming orphaned may underestimate the full impact of ARV treatment on schooling outcomes. Furthermore, this provides reassurance that the lack of a counterfactual group comprised of children in households with untreated adult AIDS patients does not produce an overestimate of the treatment impact in our empirical analysis. ${ }^{7}$ Finally, we find that the shortterm nutritional status of young children in adult patients' households improves significantly, also within six months after treatment is initiated for the patients. These gains in nutritional status can be expected to improve the physical and cognitive abilities of children and eventually, their post-school productivity levels. Together these results serve as evidence that there are substantial long-term benefits from providing ARV treatment.

The next section provides background on the treatment intervention that we study, as well as the household survey data. This is followed by a discussion in Section 3 of our strategy for estimating the impact of ARV treatment on children's outcomes. Regression results showing the effect of treatment on children's schooling and nutrition are presented in Sections 4 and 5, respectively. Section 6 concludes and discusses policy implications of this research.

\section{Background and Data}

This paper uses data from a household survey that we conducted in Kosirai Division, a rural region near the town of Eldoret, in western Kenya. The survey has been described in detail in Thirumurthy, Graff Zivin, and Goldstein (2005). In this section, we provide a brief review of the literature on ARV treatment followed by an overview of the survey and details on the schooling and nutrition data.

\subsection{Treatment of HIV/AIDS with Antiretroviral Therapy}

Almost all HIV-infected individuals experience a weakening of the immune system and progress to developing AIDS. This later stage is very often associated with substantial weight loss (wasting) and opportunistic infections such as pneumonia and tuberculosis. Once individuals develop AIDS, death is highly imminent without treatment. Median survival times are estimated to be between 5.1 months and 9.2 months (Chequer et al., 1992; Morgan et al., 2002). Opportunistic infections are generally the cause of death in AIDS cases.

\footnotetext{
${ }^{7}$ As we argue below, there is substantial medical evidence indicating that untreated AIDS patients would die within a short period. Our schooling impact results would thus be overestimates if it turned out the children's schooling also increased as the adults' experienced declining health and progressed to death (making the children orphans).
} 
Highly active antiretroviral therapy ${ }^{8}$ has been proven to reduce the likelihood of opportunistic infections and prolong the life of HIV-infected individuals. According to WHO guidelines, ARV therapy should be initiated around the time that individuals progress to AIDS (WHO, 2002). ${ }^{9}$ After several months of treatment, patients are generally asymptomatic and have improved functional capacity. Numerous studies in various countries and patient populations have reported positive results. ${ }^{10,11}$ In Haiti, patients had weight gain and improved functional capacity within one year after the initiation of ARVs (Koenig, Leandre, and Farmer, 2004). In Brazil, median survival time after developing AIDS rose to 58 months with ARV therapy (Marins et al., 2003). ARV therapy has also been highly effective at the HIV clinic where our study took place (see Wools-Kaloustian et al., 2006, as well as the results in Thirumurthy, Graff Zivin, and Goldstein, 2005).

While the effect of ARV therapy on the health of treated patients has been widely documented, much less is known about the broader impact that treatment interventions can have on the social and economic outcomes of patients and their families. Our survey in western Kenya was designed to examine these impacts.

\subsection{Household Survey Data}

Households in the survey area are scattered across more than 100 villages where crop farming and animal husbandry are the primary economic activities and maize is the major crop. The largest health care provider in the survey area is a government-run health center that offers primary care services. The health center also contains a clinic that provides free medical care (including ARV therapy) to HIV-positive patients. This rural HIV clinic (one of the first in subSaharan Africa) was opened in November 2001 by the Academic Model for the Prevention and

\footnotetext{
${ }^{8}$ In this paper, we use the terms "ARV therapy" and "ARV treatment" to refer to highly active antiretroviral therapy (HAART), which was introduced in 1996. HAART consists of three ARV medications, with a common first-line regimen of nevirapine, stavudine, and lamivudine. Generic medications that combine three ARVs in one pill (such as Triomune) have recently become available.

${ }^{9}$ Many treatment programs in developing countries, including the one that we collaborated with, have followed these guidelines. See Grubb, Perriens, and Schwartlander (2003) and Mamlin et al. (2004).

${ }^{10}$ For evidence from western countries where ARV therapy first became available, see Hammer et al. (1997), Hogg et al. (1998), and Palella et al. (1998).

${ }^{11}$ Since placebo-controlled randomized trials of ARV therapy are ethically infeasible, these studies are either observational cohort studies or randomized trials that compare regimens composed of different antiretroviral medications.
} 
Treatment of HIV/AIDS (AMPATH). ${ }^{12}$ Since late-2003, AMPATH has had adequate funding to provide ARV therapy to all patients who are eligible according to the WHO guidelines. ${ }^{13}$

We conducted two rounds of interviews between March 2004 and March 2005, with an interval of roughly six months between rounds. ${ }^{14}$ The survey sample contains two different groups of households: 503 households chosen randomly from a census of households in Kosirai Division without an AMPATH patient (random sample households) and 266 households with at least one AMPATH patient (HIV households). ${ }^{15}$ The HIV sample includes all non-pregnant patients who entered the Mosoriot HIV clinic before April 2004 and resided in Kosirai Division. To obtain a larger sample size, we also conducted in-clinic interviews with non-pregnant patients who entered the clinic before April 2004 but resided outside Kosirai Division (too far away from the clinic to be visited at home). ${ }^{16}$

Within the 266 HIV households, there are 320 individuals (including children) who are HIV-positive and known to be receiving care at the Mosoriot HIV clinic. ${ }^{17}$ Using the AMPATH identification numbers obtained from patients, we have established with the AMPATH Medical Records System (AMRS) that 224 of the 320 patients (from 206 households) began receiving ARV therapy prior to the round 2 interview. ${ }^{18}$ The remaining HIV-positive patients in our sample were not sick enough to require ARV therapy before round 2. Our analysis in this paper

\footnotetext{
${ }^{12}$ AMPATH is a collaboration between the Indiana University School of Medicine and the Moi University Faculty of Health Sciences (Kenya). Descriptions of AMPATH's work in western Kenya can be found in Mamlin, Kimaiyo, Nyandiko, and Tierney (2004) and Cohen et al. (2005).

${ }^{13}$ In response to evidence that individuals with AIDS have higher caloric needs (WHO, 2003), AMPATH also began distributing food to ARV patients during our study period. Quantities were small, but nearly two thirds of our patients received some food prior to our round 2 interview. All of the results presented in this paper remain unchanged when we control for the provision of food to treatment households.

${ }^{14}$ Round 1 was between March and August 2004. Round 2 was between September 2004 and March 2005.

${ }^{15}$ In the random sample, the HIV status of respondents is usually unknown, unless the respondent gives a self-report of having gone for an HIV test and testing HIV-positive or HIV-negative.

${ }^{16}$ In total, 81 percent of all survey households were visited at home.

${ }^{17} 274$ of these 320 HIV-positive individuals were interviewed; HIV-positive children of adult patients and HIVpositive spouses of in-clinic respondents were not interviewed. Included among these individuals are household members of respondents who were reported to be HIV-positive. The figure of $320 \mathrm{HIV}$-positive individuals excludes 15 household members who were reported to be HIV-positive by the respondent but for whom no AMPATH identification number was made available.

${ }^{18}$ We refer to the sample of households with HIV-positive patients receiving ARV treatment as "ARV households." There are 7 HIV-positive individuals whose AMPATH identification number cannot be found in the AMRS. The ARV status of these patients is therefore unknown.
} 
excludes all children known to be HIV-positive, as we are primarily interested in studying how uninfected family members are affected by the provision of ARV treatment to an adult. ${ }^{19}$

In each round of the survey, information was obtained on a range of household and individual outcomes. This included data on asset sales and purchases, housing characteristics, hours of market labor supply in the past week by each household member, children's current and past school enrollment, and children's hours of school attendance in the past week. ${ }^{20}$ For households within Kosirai Division, all of which were visited at home, measurement of the heights and weights of all resident children under the age of 5 years was also obtained. ${ }^{21}$ In this paper, we focus on two key outcomes recorded in the survey: children's education and nutrition

Table 1 compares the main characteristics of households in the random sample and HIV sample in round 1. On average, households in the survey area have 6 members. HIV households are significantly smaller, with about 5.5 members on average. There are also substantial differences in the demographic composition of households in the two samples, as well the characteristics of their household heads. HIV households are much more likely to be headed by single (and often widowed) women, whereas random sample households are generally headed by married men. HIV households tend to have significantly fewer resident children and more orphans. However, the number of resident children between the ages of 8-18 does not differ significantly. When we examine the wealth of households, HIV households are found to own significantly less land and livestock. This is one of several indications from the survey that they are worse off than other households in the community. ${ }^{22}$ Interestingly, the educational attainment of adults does not differ significantly between the two types of households. These baseline differences highlight the importance of our panel data, which allow us to employ a difference-in-difference approach when examining treatment impacts.

\footnotetext{
${ }^{19}$ While we do not know the HIV status of all household members of AMPATH patients, it is likely that most young children of adult AMPATH patient have been brought in for HIV testing. These children are provided the required prophylaxis and/or treatment at the HIV clinic.

${ }^{20}$ In the household visits, teams of male and female enumerators interviewed the household head and spouse as well as a youth in the household. For in-clinic interviews, all information was obtained from the AMPATH patient.

${ }^{21}$ In the second round, we also measured children who became older than five years between the first and second rounds.

${ }^{22}$ For further details on the household survey and the first round data, see Goldstein, Graff Zivin, Nangami, and Thirumurthy (2005).
} 


\subsection{Children's Education}

When analyzing schooling outcomes, we focus on children who were between the ages of 8 and 18 in round 1 . The reasons for studying this particular age group are two-fold. First, there is substantial variation in the age at which children in Kenya begin primary school. Typically, this occurs between the ages of 6 and 8, with considerable variation in the exact starting age. Since we will be examining how schooling outcomes change between rounds 1 and 2, restricting the sample to children older than 8 years allow us to focus on children who are very likely to be of school-going age during the survey period. Likewise, children above the age of 18 are much less likely to be enrolled in school since it is not common for children in rural areas to obtain a university education. Older children are also more likely to leave the parental home for reasons of employment or marriage, thereby creating a selected sample of over-18 children who are household members. ${ }^{23}$

In the entire sample, there are a total of 1,342 children (from 539 households) between the ages of 8 and 18 in round 1 -consisting of 902 children in 368 random sample households, 343 children in 159 HIV households that have an adult patient who receives ARV treatment, and 97 children in 41 HIV households that have an adult patient who is not yet eligible for ARV treatment. ${ }^{24}$ Attrition of children in round 2 is minimal: information is available on 876 children from random sample households and 327 children in ARV households, representing attrition rates of 3 percent and 5 percent, respectively. ${ }^{25}$ In the random sample, attrition generally is due to relocation of the entire household. ${ }^{26}$ In the sample of ARV households, attrition generally occurs because the adult patient was not found at the clinic in round 2.

The two schooling outcomes we examine are enrollment in school and hours of school attended in the week prior to the interview. Information about these outcomes was obtained from the primary female respondent in each household (typically the spouse of the male

\footnotetext{
${ }^{23}$ For this reason, we do not focus on the schooling outcomes of children older than 18 years.

${ }^{24}$ These figures indicate that a non-trivial fraction of households in our sample do not have any children between the ages of 8 and 18 in round 1: 27 percent of households in the random sample and 24 percent of households in the HIV sample. In addition, there is 1 household with an HIV-positive patient whose ARV status is unknown; this household is therefore omitted in the data analysis.

${ }^{25}$ These figures do not include children who were household members in round 1 but moved out before round 2. For these children, the primary respondent was asked about school enrollment. School attendance information, however, is generally unavailable since the primary respondent would not know how many hours of school the child attended in the past week.

${ }^{26}$ Refusal rates in the second round of the survey were below 1 percent in the random sample.
} 
household head; or the female household head in the case of single-headed households). ${ }^{27}$ It is important to distinguish between the two schooling outcomes since children can often enroll in a school at the beginning of the school term but not attend on a regular basis (and therefore spend very little time in school). ${ }^{28}$ Our enrollment measure indicates whether or not a child was enrolled in a school during the term in which the interview occurred. School attendance is measured as the primary female respondent's report of the number of hours of school attended by the child in the seven days prior to the interview (excluding travel time to and from the school). ${ }^{29}$

In the context of primary schooling, it is noteworthy that Kenya's Ministry of Education abolished primary school fees beginning in January 2003. Given that the new policy took effect more than one year prior to start of our study, it is unlikely that the comparisons of schooling outcomes in round 1 and round 2 will be affected by this policy change. This policy may provide some explanation for the high levels of school enrollments that we observe in the survey area, as we discuss below. It should be kept in mind, however, that secondary school fees still exist and can represent a substantial fraction of household income. Secondary school attendance may also be lower and more variable since the effective 'price' of spending time in school is greater for older kids who are more productive in the labor market. As a result, our analyses will generally distinguish between the schooling outcomes of young and old children.

\subsection{Children's Nutrition}

Anthropometry is widely recognized to be an important tool for assessing children's nutritional status (Waterlow et al., 1977; WHO Working Group, 1986; WHO, 1995). Two anthropometric indices, with different biological and statistical interpretations, are typically considered in the literature: weight-for-height and height-for-age. The former is a measure of thinness (or wasting) while the latter is measure of shortness (or stunting). ${ }^{30}$ Weight-for-height is particularly

\footnotetext{
${ }^{27}$ In cases where the respondent is an HIV-positive patient who was interviewed at the clinic, information on schooling outcomes is not necessarily obtained from the primary female in the household. For example, the respondent may be a male patient, or a female patient who is not the head or spouse.

${ }^{28}$ Primary and secondary schools in Kenya have three terms in each year. The first term begins in January and ends in April, the second term begins in May and ends in August, and the third term begins in September and ends in December.

${ }^{29}$ To emphasize the distinction between the discrete measure of school enrollment and the continuous measure of school attendance, the latter variable is generally referred to with the label "hours of school attendance".

${ }^{30} \mathrm{~A}$ third index, weight-for-age, is not widely used since it is primarily a composite of weight-for-height and heightfor-age. As a result, it cannot distinguish between acute and chronic malnutrition. See Waterlow et al. (1977) and Gorstein et al. (1994) for further discussion.
} 
sensitive to short-term growth disturbances caused by factors such as inadequate food and illnesses. As such, it represents a current estimate of nutritional status and can exhibit considerable variation over short periods of time. Height-for-age represents the cumulative effects of previous growth disturbances. Since growth in height is a much slower process than growth in body mass, a shortfall (or catch-up) in height-for-age will generally be slow to emerge, especially for children older than 2 years (Gorstein et al., 1994; WHO Working Group, 1986). For these reasons, weight-for-height is particularly well-suited for examining the short-term nutritional changes of interest in this paper. The primary outcome we examine is the weight-forheight Z-score, which is based on comparisons to the NCHS/CDC reference population of children in the U.S. ${ }^{31}$ For a child with a given weight and height, the Z-score is calculated by subtracting the median weight of children in the reference population with the same height (as well as same age group and sex) and then dividing by the standard deviation in the reference population. The anthropometric indicators of children in the study population thereby remain comparable to each other and can also be compared to the reference population.

As noted above, the heights and weights of children less than 5 years of age were measured during all household visits in each round. Although we conducted household visits for all non-pregnant HIV-positive patients that resided within Kosirai Division, the total number of these households is small (and not all of them have children under the age of 5 years). Thus, among HIV households that have an adult ARV recipient, a total of only 41 uninfected children were measured in both rounds. In the random sample, 349 children were measured in both rounds. ${ }^{32}$ Despite the relatively small sample sizes, in Section 5 we use the anthropometric data to examine what happens to the nutritional status of children as a result of providing ARV treatment to adults in their households.

\footnotetext{
${ }^{31}$ The comparison to well-nourished children in the U.S. is a common practice when analyzing anthropometric data from developing countries, where reference standards based on data from well-nourished children are generally not available. For a discussion of this reference population, see Gorstein et al. (1994) and WHO (1995).

${ }^{32}$ These sample sizes are smaller than those reported in Table 1 for several reasons. In the random sample and ARV sample, absence on repeated visits and attrition from the sample are among the reasons why the number of children used in our analysis is smaller than the number of children between 0-5 years in round 1. In the ARV sample, many children were not measured because households were outside the survey area of Kosirai Division and therefore not visited at home. Children who are themselves HIV-positive and are receiving care at the HIV clinic are also excluded from our analysis.
} 


\section{Empirical Strategy}

This section describes how we identify the effect of treatment on children's schooling and nutritional status. In particular, we discuss the methods used to analyze the longitudinal survey data on the outcomes of children living with HIV-positive adults who receive ARV treatment.

\subsection{Empirical Strategy for Schooling Outcomes}

The reduced form treatment effect is identified by comparing schooling outcomes of children in ARV households in round 1 and 2. When attributing changes in enrollment and hours of attendance between rounds to the provision of treatment to an adult household member, however, it is also necessary to control for other time-varying factors that influence schooling outcomes. In the rural setting that we study, these factors include seasonal fluctuations in weather, labor demand, and food availability. We control for these factors by using data from children in the randomly selected households and by including a full set of month-of-interview indicators in the schooling equations. We also include individual fixed effects to control for time-invariant characteristics of children and their households that might influence levels of school enrollment and attendance. Specifically, the following equation is estimated with longitudinal data for children in the ARV and random sample households:

$$
S_{i h t}=\alpha_{i h}+\beta_{1}\left(A R V H H_{h} * R O U N D 2_{t}\right)+\beta_{2} \text { ROUND }_{t}+\sum_{\tau=1}^{10} \gamma_{\tau} \text { MONTH }_{t}^{\tau}+\varepsilon_{i h t} .
$$

$S_{i h t}$ is the schooling outcome of interest for child $i$ in household $h$ at time $t$ (round 1 or 2 ), $\alpha_{i h}$ is a fixed effect for individual $i$ in household $h, A R V H H_{h}$ is an indicator variables equal to 1 if household $h$ has an adult who began ARV therapy at any time before round two, and ROUND $2_{t}$ indicates whether the observation is from round 2. The round 2 indicator along with the ten month-of-interview indicator variables (with one month from each round omitted to avoid collinearity with the round 2 indicator) control for monthly fluctuations in schooling outcomes in the entire community. The coefficient of interest, $\beta_{1}$, measures the change in schooling levels (between round 1 and round 2) that is due to the adult patient being treated. This strategy is tantamount to a difference-in-difference estimation strategy in which the treatment group consists of children in ARV households and the "control" group consists of children in the random sample.

Earlier work has documented a highly non-linear temporal pattern in the health status and labor supply of patients after ARV treatment is initiated, with the largest impacts occurring 
within the first six months of treatment (Thirumurthy, Graff Zivin, and Goldstein, 2005). As such, we take advantage of variation in the treatment initiation date within our sample to estimate heterogeneous treatment effects on schooling. ${ }^{33}$ We divide the sample of children in ARV households into two sub-samples of (a) children living with adult patients who had been receiving treatment for more than 100 days in round 1, and (b) children living with adult patients who had been receiving treatment for less than 100 days in round 1, including those who began receiving treatment between round 1 and round 2. Using individual fixed effects and month-ofinterview controls, we then estimate the following equation to examine whether children in the two sub-samples have different changes in enrollment and attendance levels between rounds:

$$
\begin{aligned}
S_{i h t}=\alpha_{i h}+\beta_{1}\left(\text { ARVHH }_{<100, h} *\right. & \left.R O U N D 2_{t}\right)+\beta_{2}\left(\text { ARVHH }_{>100, h} * \operatorname{ROUND}_{t}\right) \\
& +\beta_{3} \text { ROUND }_{t}+\sum_{\tau=1}^{10} \gamma_{\tau} \text { MONTH }_{t}^{\tau}+\varepsilon_{i h t} .
\end{aligned}
$$

$A R V H H_{<100, h}$ and $A R V H H_{>100, h}$ are indicator variables equal to 1 if household $h$ has an adult who was receiving ARV therapy for less than or more than 100 days, respectively, at the time of the round 1 interview. The coefficient $\beta_{1}$ would indicate whether the treatment effect occurs soon after treatment is initiated, while the coefficient $\beta_{2}$ would indicate whether an effect is evident in the later stages of treatment.

The results from estimating the reduced form equations above will reveal how ARV treatment ultimately affects the schooling outcomes of children in treated patients' households. Since the survey recorded information on the hours of market labor performed by children in the week prior to interview, we can also examine how the effect of treatment on hours of school attended compares to the effect of treatment on market labor supply. Thus, as an extension of our analysis, estimate equations 1 and 2 with the children's labor supply, rather than their school attendance, as the primary dependent variable.

\subsection{Empirical Strategy Using Orphans in Random Sample as Comparison Group}

The primary estimation strategy above is unlikely to reveal the 'true' impact of ARV treatment because our data do not contain a control group of households with AIDS patients who do not receive ARV treatment. Children's schooling outcomes under the counterfactual scenario of no treatment are therefore unobserved. However, as discussed earlier, there is an extensive medical

\footnotetext{
${ }^{33}$ Among the adults who began receiving ARV therapy before round 2, roughly half began treatment more than 100 days before round 1. The other half began treatment less than 100 days before round 1 or between round 1 and round 2 .
} 
literature showing that untreated individuals with AIDS have extremely low life expectancy, as well as growing evidence that children in Africa experience declining school attendance in the periods before and after they become orphans. Thus our results under the estimation strategy above are likely to be underestimates of the impact of treatment.

As a step toward comparing the outcomes of children in treatment households to the relevant counterfactual group, we make use of data from the 79 children in the random sample who are orphans. While information about their parent's death is generally limited, the schooling trends of orphans in the random sample may be a close representation of what would happen to children in treatment households under the "no treatment scenario." We therefore estimate equations 1 and 2 for a restricted sample consisting only of children in treatment households and orphaned children in the random sample. One potential weakness of this approach relates to the absence of information on the timing of parental death. If the parents of orphans in the random sample died long ago, any effect of parental death on schooling trends may have run its course before round 1 of the survey and the data on orphans would therefore be a poor representation of the counterfactual. ${ }^{34}$

\subsection{Empirical Strategy for Children's Nutrition}

To analyze the anthropometric data, we follow the standard practice of constructing weight-forheight standard deviation scores (Z-scores) using the 1978 NCHS/CDC reference population of children in the U.S. This index compares the weight of a boy or girl to the median weight of boys or girls in the reference population with the same height. Thus, a negative Z-score indicates that a child is thinner than the median child in the US population.

The effect of ARV treatment on the anthropometric outcomes of children living with treated patients is estimated by an empirical strategy similar to the one outlined above for schooling outcomes. In particular, we use the longitudinal data to estimate an equation with age controls and individual (child) fixed effects:

$$
\begin{aligned}
\text { WHZ }_{i h t}=\alpha_{i h}+\theta_{1} A_{\text {GEmths }}^{6-12 t} & +\sum_{\kappa=2}^{6} \theta_{\kappa} A G E y r s_{i h t}^{\kappa}+\beta_{1}\left(\text { ARVHH }_{h} * \text { ROUND }_{t}\right) \\
& +\beta_{2} \text { ROUND }_{t}+\sum_{\tau=1}^{10} \gamma_{\tau} \text { MONTH }_{t}^{\tau}+\varepsilon_{i t} .
\end{aligned}
$$

\footnotetext{
${ }^{34}$ In our sample, the school attendance levels of random sample orphans are similar to those of children in ARV households at baseline and declining between survey rounds, providing suggestive evidence that parental death was relatively recent.
} 
$W H Z_{\text {iht }}$ is the weight-for-height Z-score of child $i$ in household $h$ at time $t$ (round 1 or round 2), $A R V H H_{h}$ indicates whether household $h$ has an adult ARV recipient, and ROUND2 $2_{t}$ is an indicator for observations from round 2.35 This contrasts the trend in nutritional status of children in ARV households with that of children in the random sample of households. Data from the latter group of children allows us to control for the sensitivity of the weight-for-height Z-score to age and to seasonal patterns in food availability. We also estimate a revised version of equation 3 that allows for heterogeneous treatment effects among children in early-stage and later-stage treatment households. Finally, because there are only 16 children in the random sample under the age of 5 who are reported to be orphans, we do not compare outcomes of children in treatment households to orphans in the random sample.

\section{Results for Children's Schooling}

School enrollment rates in the survey area are extremely high, as the summary statistics in Table 2 indicate. Among all children in the random sample between the ages of 8 and 18 in round 1, 95 percent were reported as being enrolled in school. ${ }^{36}$ However, this conceals significant differences in enrollment rates between primary and secondary school-aged children. There is nearly universal enrollment among children between the ages of 8 and 14 years, but enrollment rates decline for older children. Enrollment differences between children in the ARV households and the random sample of households are small and statistically insignificant, in round 1 as well as round 2 .

The high enrollment rates for younger children are similar to findings from earlier surveys of school enrollment in Kenya (Yamano and Jayne, 2005; Evans and Miguel, 2005). ${ }^{37}$ These rates are also consistent with the more recent figures from the nationally representative 2003 Demographic and Health Survey (Central Bureau of Statistics, 2004). The DHS data indicate that in rural Kenya nearly 90 percent of children between the ages of 6 and 15 were attending school in 2003. It is noteworthy, however, that the high enrollment rates found in the DHS may partly be driven by the nationwide abolition of primary school fees shortly before the

\footnotetext{
${ }^{35}$ Following guidelines in Waterlow et al. (1977) for samples of our size, we use a set of one-year age indicators for children older than 1 year and six-month age indicators for children younger than 1 year.

36 The sample used excludes a small number of children for whom enrollment information is available but attendance information is unavailable. This is likely to be the case for children in boarding schools, since the respondents are unlikely to know the number of hours attended in the past week.

${ }^{37}$ Both studies report average enrollment rates nearing 90 percent for children less than 14 years of age. The study by Evans and Miguel (2005) also took place in western Kenya and found enrollment rates of 98 percent in 1998.
} 
survey was conducted. The absence of fees makes enrollment inexpensive, but the costs of regular attendance can be much more substantial. These include the variable costs of school materials, daily transportation to and from school in some cases, and most importantly, the opportunity costs of time spent in school. Thus, a better measure of schooling, particularly for primary school children, requires an additional focus on school attendance.

As discussed in Section 2, school attendance is measured as the total number of hours that the child spent in school during the seven days prior to the interview. Respondents were then asked follow-up questions about whether the reported hours of school attendance for the child was unusual, and if so, the reason why it was unusual. Since a significant number of respondents were interviewed during (or shortly after) school holiday periods, it is therefore important to control for the presence of holidays during the recall period. To address this complication in our analysis, we focus on a restricted sample of children in households for which interviews occurred during non-holiday periods. ${ }^{38}$ Since the survey did not collect information on the number of days in the past week that were school holidays, we do not pursue an alternate strategy of keeping all the observations of unusual hours of attendance due to holidays and including a dummy variable that indicates whether the past week contained school holidays. ${ }^{39}$

Table 2 reports the summary statistics for hours of attendance in the restricted sample that excludes children who were reported to have low attendance because of school holidays. The summary statistics indicate that differences in hours of attendance between children in random sample and ARV households are negligible. Children in both household samples attend school for an average of about 34 hours in round 1 (unconditional on enrollment). Figures 1 and 2 display non-parametric regressions of school hours attended on age, unconditional and conditional on enrollment, respectively. ${ }^{40}$ The differences between boys and girls are minor, except that older girls appear to have lower hours of attendance than older boys. In a pooled regression with additional controls, however, these differences are not statistically significant.

\footnotetext{
${ }^{38}$ We also exclude cases in which respondents reported that children did not go to school because Class 8 exams were being held in late November. This is the nationwide exam taken to enter secondary school, and most primary schools in the survey area did not hold school for children below Class 8 during the day of these exams.

${ }^{39}$ The inclusion of month-of-interview (or week-of-interview) indicators is also an inadequate control for the effect of school holidays on weekly hours attended. This is because there appears to be variation in school holidays across schools/locations. The use of children from the random sample as a control group to absorb the effects of such variation is not feasible, as the required set of location-date indicators would leave us with inadequate power to control for these effects.

${ }^{40}$ The regression uses an Epanechnikov kernel, with a bandwidth of 3 hours.
} 
Several of these results are reported below. The unconditional and conditional age-attendance patterns are very different because older children are significantly less likely to be enrolled in school, but conditional on being enrolled, older children are likely to have longer school days (as a result of being enrolled in secondary schools rather than primary schools).

Figure 3 displays non-parametric regressions of school hours attended on age for children in random sample and ARV households, in round 1 and round 2. It is evident in Figure 3 (and Table 2) that average hours attended are lower in round 2, for both the random sample and the ARV sample. The most likely explanation for this stems from the fact that round 2 was conducted during the harvest period, when children generally spend more time working on the farm. Regardless of the reason for this decline in hours of school attendance, the advantage of our empirical approach, which makes use of a comparison group of children in the random sample, is that secular patterns in hours of attendance will not result in biased estimates of the response to ARV treatment. Figure 3 also shows that whereas younger children in ARV households have slightly lower hours of attendance than children in the random sample of households during round 1, they have higher hours of attendance in round 2. Estimating the size of such increases in attendance will be the focus of the main empirical strategy employed in this paper.

To identify the major correlates of school enrollment and hours of attendance, we estimate cross-sectional regressions on our sample of children between the ages of 8 and 18 years in round 1. All of the regressions also include a full set of month-of-interview indicators to control for seasonality. The hours of attendance regressions are not conditional on enrollment. ${ }^{41}$ The results in Table 3 show that there are no significant differences in schooling outcomes between boys and girls. Compared to children who are 18 years old in round 1, younger children are significantly more likely to be enrolled. Hours attended (unconditional on enrollment) are also higher for younger children, with the peak occurring for children between 11-14 years.

Parental education and family background are recognized as being strongly associated with children's education (e.g. Behrman, Foster, Rosenzweig, and Vashishta, 1999, see Strauus and Thomas, 1995 for one overview). The results in Table 3 verify that this association holds in our survey data as well. The amount of land owned by the child's household is positively

\footnotetext{
${ }^{41}$ It is not instructive to examine school attendance conditional on enrollment in both rounds of data since changes from no attendance to some attendance (or vice versa) could represent important treatment effects. Very few children are reported to be not enrolled in both rounds.
} 
associated with enrollment and hours of attendance. Years of schooling completed by the child's father and mother also has a positive association, with father's schooling being more strongly related than mother's schooling. ${ }^{42}$ Consistent with the evidence on orphans cited earlier, we find that children whose mother is not a household member are at a significant educational disadvantage.

Finally, we focus on the outcomes of children living with ARV recipients. Table 3 shows that in round 1, children in households of patients who have just begun ARV treatment attend significantly fewer hours of school than children in the random sample. In round 2, such differences are not found. Thus, it seems that children in these ARV households experience a relative increase in the amount of time spent in school between rounds, compared to other children in the sample. The next section examines the magnitude and significance of these changes in schooling patterns.

\subsection{Main Results with Child Fixed Effects}

Since the estimates in Table 3 may be biased due to omitted variables that are correlated with the indicator of whether the child lives in a household with an HIV-positive adult receiving ARV treatment, we use the longitudinal data to estimate equations 1 and 2. As discussed earlier, both of these equations include individual fixed effects.

Columns 1 and 3 of Table 4a show the average treatment effect on school enrollment and hours of school attendance, respectively, for children in all ARV households. There is no change in these children's enrollment rates during the six months between rounds 1 and 2, but there is a large and significant increase of 4.39 hours in weekly school attendance. This represents a 13 percent increase relative to the average weekly hours attended by these children in round 1. This result is thus the first indication that the provision of ARV treatment has a positive effect on school outcomes of children living in treated patients' households.

Table $4 \mathrm{a}$ also presents results from estimating equation 2, which tests for heterogeneous effects that correspond to the length of time that patients have been receiving ARV treatment. Again, no effect on school enrollment is found (column 2), a result that is perhaps not surprising given the low costs of enrollment and the high levels of enrollment for all children at baseline. For hours of attendance however, there is significant heterogeneity in the treatment effects. As

\footnotetext{
${ }^{42}$ Since the survey did not collect information on parents' schooling for orphans and foster children, we use an imputed value equal to the mean of father's or mother's schooling in the entire sample. We also include dummy variables indicating whether an imputed value is used.
} 
column 6 shows, the increase in hours of attendance between rounds is particularly large for children in households of adults who are just beginning treatment in round $1\left(A R H H_{<100}\right)$. The average increase in weekly hours attended is 6.66 hours for these children (representing a 21.8 percent increase relative to their average attendance level in round $1^{43}$ ). For children in households with an adult who started treatment at least 100 days prior to round $1\left(A R H H_{>100}\right)$, there is no significant change in weekly hours attended. Taken together, these results suggest that children in ARV households experience the largest increase in hours of attendance within six months after treatment is initiated for the adult. In subsequent periods, they experience no additional changes, but they continue to maintain their initial increase in attendance. A striking feature of these results is their consistency with the large health and labor supply response to ARV treatment among adult AIDS patients (see Thirumurthy, Graff Zivin, and Goldstein, 2005). Given the previous finding that patients' health improves and labor supply increases soon after the initiation of treatment, these results suggest that the resulting income effect and decrease in care-giving burden allows children to spend more time in school. ${ }^{44}$

In Kenya, as in many developing countries, work and household responsibilities are frequently gender- and age-specific. Thus, when an adult becomes healthier and returns to work, the magnitude of the income and substitution effects that operate on household members and the extent to which they translate into changes in schooling outcomes may depend on their age and sex. $^{45}$ In Table 4a, Columns 3, 4, 7, and 8 show the results from testing for heterogeneous effects by sex. When we examine all ARV households together (columns 3 and 4), the results suggest that only boys experience a significant increase in attendance (of 6.74 hours). ${ }^{46}$ However, when we control for the length of time that the adult patient has been on treatment (columns 7 and 8), we find that there are significant increases in hours of attendance for both boys and girls. The increase in school attendance of 9.14 hours for boys is especially large,

\footnotetext{
${ }^{43}$ The average hours attended is 30.47 for children in households with adult ARV recipients who had been on treatment for less than 100 days in round 1 or who began treatment shortly after round 1 (represented by $A R V H H_{<100}$ in equation 2).

${ }^{44}$ The absence of any effect on school enrollment rates (columns 1 and 2 in Table 4a) suggests the provision of treatment results in improved school attendance among children already enrolled in school.

${ }^{45} \mathrm{We}$ might also expect the effect of treatment to depend on the gender of the treated patient, but preliminary analysis indicates that this is not the case. However, given that nearly 75 percent of adult ARV recipients in our sample are women, we may not have large enough sample sizes to detect significantly different effects between male and female patients.

${ }^{46}$ In results that are not reported, we find that the treatment effects are generally not dependent on the amount of land owned by the household (a common measure of wealth in the area). However, we do find that for girls living in treatment households that do not own any land, there is a significant increase in hours of school attendance.
} 
representing a 30 percent increase relative to their average attendance level in round $1 .^{47}$ In both cases, the increase in hours of attendance occur within roughly six months after the initiation of treatment.

In table $4 \mathrm{~b}$, we test for further heterogeneity in treatment effects by reporting the results for boys and girls of different age groups, focusing on primary school age children (ages 8-14 in round 1) and older children (14-18 in round 1). ${ }^{48}$ We again find no significant changes in school enrollment rates of children in ARV households. Reported school enrollment is nearly universal for young girls and there is no variation between rounds, making it impossible to estimate a treatment effect. In contrast to the previous results for all boys and girls, we do not find many significant changes in hours of attendance at this disaggregated level. The lone exception is for young boys, who experience a large and significant increase of 11.39 hours in weekly attendance within roughly six months after the initiation of treatment (column 2). It is important to note, however, that our power to detect significant changes in hours of attendance is somewhat compromised by the fairly small sample sizes of children in each age-sex group.

To put these results in perspective, it is worth comparing the magnitudes of the treatment effect on hours of school attendance (particularly those reported in Table 4a) to the treatment effect on children's weekly hours of market labor supply. Table 5 therefore presents the results from estimating equations that identify the effect of ARV treatment on labor supply. The equations estimated are similar in form to equations 1 and 2, with hours of market labor performed in the week prior to interview as the dependent variable. Data from children in the random sample are again used to control for aggregate seasonal effects on labor supply.

Column 1 of Table 5 shows that on average, there is a large and significant reduction of 4.5 hours between round 1 and round 2 in the weekly market labor supply of children living in households of ARV recipients. ${ }^{49}$ This is remarkably close to the estimated increase of 4.4 hours when the analogous equation is estimated for weekly hours of school attendance (see column 4 of Table 4a), suggesting a near-perfect crowd-out of work for school in response to improvements in adult health in the household. These results are particularly striking since for

\footnotetext{
47 The average hours attended are 30.15 for boys in households with adult ARV recipients who had been on treatment for less than 100 days in round 1 or who began treatment shortly after round 1.

${ }^{48}$ The results below are robust to different definitions of these young and old age groups (with cutoffs at 12 and 13 years). The cutoff of 14 years is chosen since it is typically the age when children complete primary school.

${ }^{49}$ The results presented here differ only slightly from those in Thirumurthy, Graff Zivin, and Goldstein (2005), as our analysis here is restricted to children in households that were interviewed during non-holiday periods.
} 
each child, the information on hours of school attendance in the past week and hours of market labor supply in the past week was obtained from the household's primary female and male respondent, respectively, in separate interviews. ${ }^{50}$ Turning to the temporal pattern in labor supply changes, column 4 of Table 5 shows that the average change in the labor supply of all children in ARV households occurs soon after treatment is initiated for the adult patient, and that significant reductions in labor supply continue to occur in the later stages of treatment as well.

Looking beyond average effects for all children in ARV households, columns 2, 3, 5, and 6 reveal larger and significant reductions in labor supply for boys and no significant changes for girls. For boys in all ARV households, there is an average decrease in market labor supply of 7.72 hours per week in the six months between survey rounds (column 2 of Table 5). This is quite close to the estimated increase of 6.74 hours in weekly school attendance (column 4 or Table 4a). For boys in households of patients who are in the early stages of treatment, the estimated decrease in market labor supply ( 8.0 hours) also remarkably similar to the estimated increase in weekly school attendance ( 9.14 hours). The continued decline in the labor supply of boys in the later stages of adult treatment is not accompanied by a corresponding increase in hours of school attendance. The lack of any treatment effect on the market labor supply of girls should be interpreted with caution. Girls in the survey area spend significantly more time in non-market labor activities (such as household chores and care-giving) than market ones. If girls experience decreases in their non-market labor supply when an adult household member becomes healthier due to ARV treatment, this will not be captured in the market labor supply measures reported in Table 5. The evidence in this paper on girls' school attendance is consistent with such a time re-allocation pattern for girls (although we lack data on non-market labor supply to test whether this is actually the case). ${ }^{51}$

In summary, the results in this section indicate that the provision of ARV treatment to adults results in significant increases in hours of school attendance for children living with the patients. For boys, these results are very consistent with the evidence that treatment also results in a decrease in their market labor supply. In particular, the effects on hours of attendance occur almost exclusively through reallocations of their time away from market labor supply. For girls,

\footnotetext{
${ }^{50}$ In addition, the respondents were also interviewed by different interviewers.

51 The survey did not collect information on non-market labor supply in round 2, thereby making it impossible to examine how time allocation to non-market activities was affected by the provision of ARV treatment.
} 
the schooling increases do not appear to be driven by changes in their market labor supply, suggesting a reallocation of time from non-market labor supply and/or leisure.

\subsection{Results Based on Comparison to Orphans in the Random Sample}

As discussed in Section 3.2, an alternative comparison group for children in ARV households is orphaned children in the random sample. Since there are 79 orphaned children in the random sample, we can examine schooling levels over time for the two groups of children using the specification described by equation $2 .^{52}$ Table 6 a presents these results. The main finding is that the effect of ARV treatment on hours of attendance is much larger than the effects reported in Section 4.1. As we might expect, the treatment effect increases when the comparison group resembles what would happen to children under the counterfactual scenario of no treatment.

Column 1 of Table 6a shows that for all children in ARV households, hours of attendance increase significantly between round 1 and round 2 . The increase in hours of attendance is larger for children in households of patients who are in the early stages of treatment- the increase of 10.67 hours is nearly two times the effect estimated previously and it represents a 35 percent increase relative to these children's average attendance level in round 1 of 30.47 hours. Columns 2 and 3 show that the increase in hours of attendance is significant for both boys and girls, respectively. The point estimates for boys and girls in households of patients in the early stages of treatment are again considerably larger than before, at 15.69 and 10.8 hours respectively (compare to 9.14 and 6.36 hours in Table 4a). In contrast to the previous results, a positive and significant effect on hours of attendance is also observed for children in households of patients in later-stages of treatment in round 1. Thus, relative to orphans in the random sample, children in households of adult ARV recipients experience increases in hours of attendance that continue to occur well beyond the first six months of treatment. Finally, columns 4-7 make clear that these schooling impacts are concentrated on children of primary school age.

As noted earlier, a large fraction of adult patients at the HIV clinic are women who have lost their husbands (most likely due to AIDS) and as a result, many children in the ARV households have already been orphaned. Since the orphaned children in ARV households may resemble the orphans in the random sample to some degree, we instead compare the schooling outcomes of non-orphans in treatment households to those of orphans in the random sample. By

\footnotetext{
${ }^{52}$ As noted earlier, in the scenario of no treatment for the adult patients, there is a large literature that suggests the children would be orphaned and that their schooling outcomes would decline.
} 
focusing on non-orphans in the ARV households, we are considering a group of children who are very likely to become orphans between round 1 and round 2 (or shortly after) were it not for the provision of ARV treatment to the adult patient. As shown in Table 6b, compared to the orphans in the random sample, a large and significant increase in hours of attendance is found for the non-orphans in treatment households. Column 1 shows that there is an increase of 9.46 hours in the school attendance for orphans in households of ARV recipients who are in the early stages of treatment. This increase is similar to the one found for all children (orphans and non-orphans) in these households (column 1 of Table 6a), as are the increases for boys and girls in these households (columns 2 and 3 of Tables $6 a$ and $6 \mathrm{~b}$ ). Given the increasingly small number of observations, the precision of the estimates is compromised considerably when we examine subgroups of children (columns 4-7). The results in Tables $6 \mathrm{a}$ and $6 \mathrm{~b}$ nonetheless illustrate that the impact of ARV treatment on hours of school attendance of children in treated households is considerably larger when we compare these children to the "counterfactual" group of orphans in the survey area.

\section{Results for Children's Nutrition}

As ARV treatment improves the health and employment outcomes of adult HIV-positive patients, outcomes other than time allocation of children (to labor and schooling) are also likely to be affected. In particular, an income effect from the increased labor supply of the adult patient may affect the nutritional status of household members. Specifically, we examine whether there is a change in the nutritional status of very young children (age 0-5 years) residing in the households of adult ARV recipients.

Table 7 presents summary statistics of weights and heights for all children measured in both rounds of the survey. Despite low baseline measures for children in ARV households, the mean weight-for-height Z-score of children between the ages of 0-5 years is not statistically different from that of children in the random sample of households (in either of the two survey rounds). This focus on means, however, masks important differences in the tails of the distribution. The simple cross-sectional comparisons show that 12 percent of children in ARV 
households exhibit wasting (Z-score below -2.0) in Round 1, significantly more than the 4 percent in the random sample. Suggestively, these differences disappear in Round 2. ${ }^{53}$

Some of these patterns are also evident in Table 8, which reports results from regressing the weight-for-height Z-score (for each round separately) on a set of individual and household characteristics. $^{54}$ The non-linear growth pattern for children is reflected in the various age coefficients, which indicate that Z-scores are initially high but decline in the first year after birth. Column 1 shows that in the first round, children living in ARV households have lower weightfor-height on average than children in the random sample of households, but the difference is not statistically significant. We then divide the sample of children in ARV households as before, on the basis of treatment duration when the round 1 interview occurred. Column 2 shows that children in both treatment groups have lower Z-scores in round 1, but the differences are not statistically significant. Examining the nutritional status of the same children in round 2 (columns 3 and 4 of Table 8), we find that children in ARV households are relatively better off in comparison to round 1 . Column 4 shows that this is true for children in both groups of ARV households.

To investigate changes in nutritional status more thoroughly, we estimate equation 3 using the longitudinal data. We also include fixed effects for the interviewers who measured the children. $^{55,56}$ As column 1 of Table 9 indicates, children in ARV households have higher Zscores in round 2 , but the point estimate of 0.25 is not statistically significant. However, previous work found that patients experience the largest clinical and labor market impacts soon after the initiation of ARV treatment (Wools-Kaloustian et al., 2006; Thirumurthy, Graff Zivin, and Goldstein, 2005). If these improvements translate into increased family income, there is reason to expect that short-term nutritional status should improve most for children in households of adult patients beginning to receive treatment in round 1. As column 2 of Table 9 indicates, this is exactly the pattern we observe. Children residing with patients who began ARV therapy less than 100 days prior to round 1 have a large and significant increase in their weight-

\footnotetext{
${ }^{53}$ Table 7 also reports substantial variation in Z-scores by age group, as has been reported in other studies (Waterlow et al., 1977).

${ }^{54}$ Seasonal variations in weight-for-height are common (WHO Working Group, 1986), so we control for seasonality here and when analyzing changes in weight-for-height.

${ }^{55}$ Following the recommendations in WHO (1995), the 9 observations with weight-for-height Z-score or height-forage Z-score larger than 6 or smaller than -6 are excluded from the analysis.

${ }^{56}$ Interviewer fixed effects are included here because anthropometry, particularly measuring heights in small children, is challenging and can vary with individual skills and experience.
} 
for-height Z-score between rounds. The magnitude of the point estimate is worth emphasizing. Weight-for-height of children living with early-stage treatment recipients improves by 0.57 standard deviations in the six months between rounds 1 and 2, which more than erases the "pretreatment" discrepancy in nutritional status that was observed in round 1. Children in other ARV households, on the other hand, have no significant change in Z-scores. The large magnitude of the improvement in weight-for-height soon after initiation of ARV treatment is consistent with the fact that it is a measure of current nutritional status and is known to be sensitive to short-term changes in the availability of food and other factors that affect growth. ${ }^{57,58}$

While the results in columns 1 and 2 inform us about the average change in weight-forheight Z-score among children in treatment households, the effect of treatment on children with extremely low Z-scores in round 1 is of special interest given the potential long term effects of extreme malnutrition. We examine this by looking at how the fraction of children at the bottom of the distribution (those with Z-scores below -2.0, i.e. wasting) responds to the provision of treatment. In columns 3 and 4 of Table 9, we define the dependent variable as an indicator variable of whether a child's Z-score is below -2.0. The results show that there is indeed a significant decline in wasting among young children living in households of ARV treatment recipients - in column 3, we see that the likelihood that a child is wasted declines by 9 percentage points across all treatment households. As column 4 shows, the treatment effect is more pronounced for children residing with patients who began ARV therapy more than 100 days prior to round 1. For children in early-stage treatment households, the decline in the likelihood of wasting is not statistically significant. These latter results suggest that, for children in the bottom of the distribution - those that have a larger amount of catching up to do - the effects can manifest well into the course of a household member's treatment.

Considering the growing evidence that early childhood nutrition affects cognitive abilities later in life (Alderman, Behrman, Lavy, and Menon, 2001; Glewwe, Jacoby, and King, 2001; Glewwe and King, 2001), the results in Table 9 are especially noteworthy. The impact of

\footnotetext{
${ }^{57}$ The estimates can also be compared to the estimated effect of South Africa's Old Age Pension program on the nutritional status of children living with pension recipients. In this program, women older than 60 years and men older than 65 years receive a large monthly pension. Duflo (2003) finds that pensions received by women increased the weight-for-height of girls by 1.19 standard deviations.

${ }^{58}$ Since height-for-age is an anthropometric index that changes slowly, children are unlikely to experience large changes over the course of six months. When examined as an outcome variable, it is reassuring that we find no significant changes in the height-for-age Z-scores of children living with ARV recipients.
} 
treatment on the nutritional status of children in treated patients' household may well equate to being the most long-lasting social benefit from providing ARV treatment. ${ }^{59}$

\section{Conclusion}

The morbidity and mortality associated with AIDS poses a significant threat to family well-being among those infected. Our results suggest that the diminished earning capacity of HIV-infected adults along with the additional caregiver burden associated with their illness hastens the participation of children in the labor force and reduces their schooling attendance. ARV treatment, which dramatically improves the health of infected individuals, reverses these effects. Children work less and spend more time in school; very young children are better nourished. In contrast to the literature that examines more obviously temporary health and income shocks, we find the impacts on children's schooling and nutrition to be especially large. Indeed, the magnitude of the effects found here suggest that the mechanisms that households use to cope with transient shocks are of little assistance in the face of what is initially perceived as a severe permanent shock - the imminent death of a household member.

Of course, our results also have important implications for how one should value investments in ARV treatment. Most research in this area denominates the returns to treatment in some metric of health, measures that are focused on morbidity and mortality impacts for patients. Even the use of quality- (or disability-) adjusted-life-years saved, which under certain conditions can capture patient income effects, still misses the important non-patient impacts described in this paper. These impacts are not small. Within six months after the initiation of treatment for HIV-infected adults, weekly hours of school attendance for children in the treated adults' households increases by over 20 percent. When these children are compared to a group that better represents the counterfactual scenario of no treatment, the schooling impacts are even larger: weekly hours of school attendance increases by 35 percent in the first six months and continues to climb thereafter. The impacts on the nutritional status of very young children are equally impressive. Given the high returns to these two forms of children's human capital, our results suggest that ARV treatment has benefits that extend well beyond those experienced directly by treated patients.

\footnotetext{
${ }^{59}$ Because of limited sample size considerations, we do not compare the children in ARV households to orphans in the random sample of households.
} 
These intergenerational impacts are not only important for family welfare, they have potentially important implications for economic growth. The increases in school attendance and improvements in the nutrition of very young children are likely to translate into higher levels of educational attainment for kids in HIV-infected households. As a result, treating the current generation of infected adults will contribute to economic growth in future years. Conversely, the absence of treatment will lead to an economic contraction. Importantly, these intertemporal economic consequences of not providing treatment would be experienced even if we divert current treatment expenditures to disease prevention efforts. Thus, the discussions of any such diversion must weigh these costs against the benefits derived from reducing prevalence rates in the future. The HIV/AIDS epidemic and our response to it exert a profound influence on household investment decisions today, creating an inextricable link between the welfare of current and future generations in countries heavily impacted by the disease. 


\section{References}

Alderman, Harold, Jere R. Behrman, Victor Lavy, and Rekha Menon. 2001. "Child Health and School Enrollment: A Longitudinal Analysis." The Journal of Human Resources 36:186-205.

Ashenfelter, Orley and James Heckman. 1974. "The Estimation of Income and Substitution Effects in a Model of Family Labor Supply." Econometrica 42:73-86.

Becker, Gary. 1965. "A Theory of the Allocation of Time.” Economic Journal 75:493-517.

Beegle, Kathleen, Joachim De Weerdt, and Stefan Dercon. 2005. "Orphanhood and the LongRun Impact on Children." Mimeo, World Bank.

Behrman, Jere R., Andrew D. Foster, Mark R. Rosenzweig, Prem Vashishtha. 1999. “Women's Schooling, Home Teaching, and Economic Growth." Journal of Political Economy 107:682714.

Bell, Clive S., Shanta Devarajan, and Hans Gersbach. 2003. "Long Run Economic Costs of AIDS: Theory and Application to South Africa." World Bank Policy Research Working Paper Series No. 3152.

Canning, David. 2006. "The Economics of HIV/AIDS in Low-Income Countries: The Case for Prevention." Journal of Economic Perspectives 20:121-142.

Case, Anne and Cally Ardington. 2005. "The Impact of Parental Death on School Outcomes: Longitudinal Evidence from South Africa." Mimeo, Princeton University.

Case, Ann and Angus Deaton. 1998. "Large Cash Transfers to the Elderly in South Africa." Economic Journal 108:1330-1361.

Central Bureau of Statistics. 1999. Kenya 1999 Population and Housing Census. Nairobi: Central Bureau of Statistics.

Central Bureau of Statistics. 2004. Kenya Demographic and Health Survey 2003. Nairobi: $C B S$.

Chequer, P. et al. 1992. "Determinants of Survival in Adult Brazilian AIDS Patients, 19821989." AIDS 6:483-487.

Coetzee, David et al. 2004. "Outcomes After Two Years of Providing Antiretroviral Treatment in Khayelitsha, South Africa." AIDS 18:887-895.

Cohen, Jonathan et al. 2004. "Addressing the Educational Void During the Antiretroviral Therapy Rollout," AIDS 18:2105-2106. 
Duflo, Esther. 2001. "Schooling and Labor Market Consequences of School Construction in Indonesia: Evidence from an Unusual Policy Experiment." The American Economic Review 91:795-813.

Duflo, Esther. 2003. "Grandmothers and Granddaughters: Old-age Pensions and Intrahousehold Allocation in South Africa." World Bank Economic Review 17:1-25.

Evans, David and Edward A. Miguel. 2005. "Orphans and Schooling: A Longitudinal Analysis." UC-Berkeley Center for International and Development Economics Research Paper C05-143.

Goldstein Markus, Joshua Graff Zivin, Mabel Nangami, Harsha Thirumurthy. 2005.

"HIV/AIDS and Socio-economic Status: Preliminary Evidence from Western Kenya." Mimeo, Yale University.

Glewwe, Paul, Hanan G. Jacoby, and Elizabeth M. King. "Early Childhood Nutrition and Academic Achievement: A Longitudinal Analysis." Journal of Public Economics 81:345-368.

Glewwe, Paul and Elizabeth M. King. “The Impact of Early Childhood Nutritional Status on Cognitive Development: Does the Timing of Malnutrition Matter?" The World Bank Economic Review. 15:81-113.

Gorstein, J. et al. 1994. "Issues in the Assessment of Nutritional Status Using Anthropometry." Bulletin of the World Health Organization 72:273-283.

Grubb, Ian, Jos Perriens, and Bernhard Schwartlander. 2003. A Public Health Approach to Antiretroviral Treatment: Overcoming Constraints. Geneva: World Health Organization.

Hammer, Scott M. et al. 1997. “A Controlled Trial of Two Nucleoside Analogues plus Indinavir in Persons with Human Immunodeficiency Virus Infection and CD4 Cell Counts of 200 per Cubic Millimeter or Less.” New England Journal of Medicine 337:725-733.

Hogg, Robert S. et al. 1998. "Improved Survival Among HIV-Infected Individuals Following Initiation of Antiretroviral Therapy." JAMA 279:450-454

Hogg, Robert S. et al. 2001. "Rates of Disease Progression by Baseline CD4 Cell Count and Viral Load After Initiating Triple-Drug Therapy." JAMA 286:2568-2577.

Jacoby, Hanan G. and Emmanuel Skoufias. 1997. "Risk, Financial Markets, and Human Capital in a Developing Country." Review of Economic Studies 64:311-335.

Kochar, Anjini. 1995. "Explaining Household Vulnerability to Idiosyncratic Income Shocks." The American Economic Review Papers and Proceedings 85:159-164. 
Kochar, A. 1999. "Smoothing Consumption by Smoothing Income: Hours of Work Responses to Idiosyncratic Agricultural Shocks in Rural India." Review of Economics and Statistics 81: 5061 .

Koenig, Serena P., Fernet Leandre, and Paul E. Farmer. 2004. "Scaling-up HIV Treatment Programmes in Resource-Limited Settings: The Rural Haiti Experience." AIDS 18:S21-S25.

Laurent, Christian et al. 2002. "The Senegalese Government's Highly Active Antriretroviral Therapy Initiative: An 18-month Follow-up Study." AIDS 16:1363-1370.

Mamlin, Joe, Sylvester Kimaiyo, Winstone Nyandiko, and William Tierney. 2004. Academic Institutions Linking Access to Treatment and Prevention: Case Study. Geneva: World Health Organization.

Marins, Jose Ricardo P. et al. 2003. "Dramatic Improvement in Survival Among Adult Brazilian AIDS patients." AIDS 17:1675-1682.

Miguel, Edward and Michael Kremer. 2004. "Worms: Identifying Impacts on Education and Health in the Presence of Treatment Externalities." Econometrica 72:159-217.

Morgan, Dilys et al. 2002. "HIV-1 Infection in Rural Africa: Is There a Difference in Median Time to AIDS and Survival Compared with That in Industrialized Countries?" AIDS 16:597603.

Palella, Frank J. et al. 1998. "Declining Morbidity and Mortality Among Patients with Advanced Human Immunodeficiency Virus Infection." The New England Journal of Medicine 338:853-860.

Paxson, C. 1992. “Using Weather Variability to Estimate the Response of Savings to Transitory Income in Thailand." American Economic Review 82: 15-33.

Pitt, Mark and Mark Rosenzweig. 1990. "Estimating the Intrahousehold Incidence of Illness: Child Health and Gender-Inequality in the Allocation of Time." International Economic Review 31:969-989.

Schultz, T. Paul and Aysit Tansel. 1997. "Wage and Labor Supply Effects of Illness in Cote d'Ivoire and Ghana: Instrumental Variable Estimates for Days Disabled." Journal of Development Economics 53:251-286.

Schultz, T. Paul. 1999. "Health and Schooling Investments in Africa." The Journal of Economic Perspectives 13:67-88.

Strauss, John and Duncan Thomas. 1995. "Human Resource: Empirical Modeling of Household and Family Decisions," in Jere Behrman and T.N. Srinivasan, eds. Handbook of Development Economics Vol. 3, Part 1. 
Strauss, John and Duncan Thomas. 1998. "Health, Nutrition, and Economic Development." The Journal of Economic Literature 36:766-817.

Thirumurthy, Harsha, Joshua Graff Zivin, and Markus Goldstein. 2005. "The Economic Impact of AIDS Treatment: Labor Supply in Western Kenya.” NBER Working Paper No. 11871.

Townsend, R. 1994. "Risk and Insurance in Village India.” Econometrica 62: 539-591.

Udry, C. 1994. "Risk and Insurance in a Rural Credit Market: An Empirical Investigation in Northern Nigeria." Review of Economic Studies 61.

UNAIDS. 2004. Report on the Global AIDS Epidemic. Geneva: Joint United Nations Programme on the HIV/AIDS.

Waterlow, J.C et al. 1977. "The Presentation and Use of Height and Weight Data for Comparing the Nutritional Status of Groups of Children Under the Age of 10 Years." Bulletin of the World Health Organization 55:489-498.

Wools-Kaloustian, Kara, et al. 2006. "Viability and Effectiveness of Large-scale HIV Treatment Initiatives in Sub-Saharan Africa: Experience from Western Kenya." AIDS 20:41-48.

World Health Organization. 1995. "Physical Status: The Use and Interpretation of Anthropometry. Report of a WHO Expert Committee." World Health Organization Technical Report Series 854:1-452.

World Health Organization. 2002. Scaling Up Antiretroviral Therapy in Resource-Limited Settings: Guidelines for a Public Health Approach. Geneva: World Health Organization.

World Health Organization. 2003. Nutrient Requirements of People Living with HIV/AIDS: Report of a Technical Consultation. Geneva: World Health Organization.

World Health Organization. 2006. Progress on Global Access to HIV Antiretroviral Therapy: A Report on " 3 by 5" and Beyond. Geneva: World Health Organization.

World Health Organization Working Group. 1986. "Use and Interpretation of Anthropometric Indicators of Nutritional Status." Bulletin of the World Health Organization 64:929-941.

Yamano, Takashi and T.S. Jayne. 2005. "Working-age Adult Mortality and Primary School Attendance in Rural Kenya." Economic Development and Cultural Change 53:619-653.

Young, Alwyn. 2005. "The gift of the dying: the tragedy of AIDS and the Wealth of Future African Generations." Quarterly Journal of Economics 120:423-466. 
Table 1. Summary Statistics for Children's Schooling

\begin{tabular}{|c|c|c|c|c|c|}
\hline & \multicolumn{2}{|c|}{ Random Sample } & \multicolumn{2}{|c|}{ HIV Sample } & \multirow[b]{2}{*}{$\mathrm{P}$-value } \\
\hline & Mean & Std.Dev. & Mean & Std.Dev. & \\
\hline Number of households & 503 & & 266 & & \\
\hline \multicolumn{6}{|l|}{ Household Structure (Round 1) } \\
\hline Household size & 6.04 & 2.82 & 5.45 & 2.43 & 0.0038 \\
\hline Number of children (0-18 years) & 3.12 & 2.12 & 2.79 & 1.78 & 0.0349 \\
\hline Number of children (0-5 years) & 0.85 & 0.93 & 0.65 & 0.86 & 0.0039 \\
\hline Number of children ( $8-18$ years) & 1.82 & 1.59 & 1.74 & 1.42 & 0.4910 \\
\hline Number of extended family members & 0.92 & 1.33 & 1.14 & 1.52 & 0.0432 \\
\hline Number of orphans & 0.24 & 0.70 & 0.85 & 1.39 & 0.0000 \\
\hline \multicolumn{6}{|l|}{ Household Head Characteristics } \\
\hline Age & 47.93 & 15.39 & 44.84 & 13.86 & 0.0062 \\
\hline Male & $81 \%$ & & $54 \%$ & & 0.0000 \\
\hline Single & $22 \%$ & & $50 \%$ & & 0.0000 \\
\hline Widowed & $13 \%$ & & $32 \%$ & & 0.0000 \\
\hline \multicolumn{6}{|l|}{ Asset Ownership (Round 1) } \\
\hline Quantity of land owned (acres) & 6.82 & 10.27 & 4.72 & 8.78 & 0.0054 \\
\hline Percent landless & $13.2 \%$ & & $27.2 \%$ & & 0.0000 \\
\hline Value of land owned (1,000 shillings) & 650 & 983 & 572 & 1186 & 0.3316 \\
\hline Value of livestock owned (1,000 shillings) & 61 & 93 & 37 & 67 & 0.0001 \\
\hline \multicolumn{6}{|l|}{ Educational Attainment of Adults (>18 years) } \\
\hline Number of adults & 1466 & & 706 & & \\
\hline Years of School Completed & 7.57 & 3.73 & 7.42 & 3.82 & 0.3871 \\
\hline Completed Primary School & $52 \%$ & & $51 \%$ & & 0.5686 \\
\hline
\end{tabular}

Notes: P-value from t-test for equality of means for households in random sample and HIV sample. The summary statistics are calculated after excluding individuals who joined the household between round 1 and round 2 . Individuals who left the household between round 1 and round 2 are included. The HIV sample includes 206 households that have an adult patient who began receiving ARV treatment sometime before round 2. 
Table 2. Summary Statistics for Children's Schooling Outcomes

\begin{tabular}{|c|c|}
\hline Random Sample & ARV households \\
\hline Mean Std. Dev. & Mean Std. Dev. \\
\hline
\end{tabular}

$\mathrm{N}$ (children 8-18 in round 1 )

781

307

Enrolled in School

Round 1

0.95

0.93

0.31

Round 2

0.91

0.91

0.64

Hours of School Attended in Past Week (conditional on no holiday)

$\begin{array}{llllll}\text { Round 1 } & 34.58 & (15.0) & 33.56 & (15.5) & 0.38 \\ \text { Round } 2 & 29.00 & (14.5) & 28.41 & (16.3) & 0.66\end{array}$

Hours of School Attended in Past Week (conditional on enrollment \& no holiday)

$\begin{array}{lrrrrr}\text { Round 1 } & 37.85 & (11.1) & 36.36 & (12.6) & 0.11 \\ \text { Round 2 } & 33.17 & (10.0) & 35.39 & (9.1) & 0.03 \\ \text { Interviewed during holiday period (self-report) } & & & & \\ \text { Round 1 } & 39 \% & & 11 \% & & 0.00 \\ \text { Round 2 } & 32 \% & & 52 \% & & 0.00\end{array}$

Enrollment Rates by Age group (random sample in round 1)

8-10.99 99\%

$11-13.99 \quad 99 \%$

14-17.99 92\%

Notes: P-value from t-test for equality of means for children in ARV households and the random sample of households. 
Table 3. Determinants of Children's Schooling Outcomes in Round 1 and 2

(1)

\author{
(3)
}

(4)

\begin{tabular}{|c|c|c|c|c|}
\hline \multirow[t]{2}{*}{ Dependent Variable: } & Enrollment & Attendance & Enrollment & Attendance \\
\hline & \multicolumn{2}{|c|}{ Round 1} & \multicolumn{2}{|c|}{\begin{tabular}{|l|} 
Round 2 \\
\end{tabular}} \\
\hline \multirow[t]{2}{*}{ Female } & -0.005 & 1.051 & -0.010 & 0.117 \\
\hline & $(0.018)$ & $(0.990)$ & $(0.023)$ & $(1.007)$ \\
\hline \multirow[t]{2}{*}{ Age 8-10.99 years } & 0.340 & 4.451 & 0.506 & 14.550 \\
\hline & $(0.035)^{* * *}$ & $(1.997)^{* *}$ & $(0.043)^{* * *}$ & $(1.886)^{* * *}$ \\
\hline \multirow[t]{2}{*}{ Age 11-13.99 years } & 0.352 & 10.612 & 0.503 & 16.491 \\
\hline & $(0.035) * * *$ & $(1.944)^{* * *}$ & $(0.043)^{* * *}$ & $(1.870) * * *$ \\
\hline \multirow[t]{2}{*}{ Age $14-17.99$ years } & 0.240 & 8.371 & 0.332 & 12.982 \\
\hline & $(0.033) * * *$ & $(1.876)^{* * *}$ & $(0.041)^{* * *}$ & $(1.774)^{* * *}$ \\
\hline \multirow[t]{2}{*}{ Amt of land owned (acres) } & 0.002 & 0.241 & 0.002 & 0.178 \\
\hline & $(0.001)^{* *}$ & $(0.053)^{* * *}$ & $(0.001)^{* *}$ & $(0.054)^{* * *}$ \\
\hline \multirow[t]{2}{*}{ HIV household (no ARVs) } & 0.008 & -1.357 & -0.091 & -1.587 \\
\hline & $(0.034)$ & $(1.893)$ & $(0.054)^{*}$ & $(2.368)$ \\
\hline \multirow[t]{2}{*}{ ARV household (<100 days) } & -0.029 & -3.007 & -0.044 & 1.089 \\
\hline & $(0.028)$ & $(1.567)^{*}$ & $(0.040)$ & $(1.758)$ \\
\hline \multirow[t]{2}{*}{ ARV household (>100 days) } & -0.001 & 0.853 & -0.073 & -0.110 \\
\hline & $(\mathbf{0 . 0 2 7})$ & $(1.495)$ & $(0.040)^{*}$ & $(1.748)$ \\
\hline \multirow[t]{2}{*}{ Years school - father } & 0.003 & 0.869 & 0.004 & 0.706 \\
\hline & $(0.004)$ & $(0.208) * * *$ & $(0.005)$ & $(0.199)^{* * *}$ \\
\hline \multirow[t]{2}{*}{ Years school - mother } & 0.002 & 0.511 & 0.002 & 0.301 \\
\hline & $(0.003)$ & $(0.175)^{* * *}$ & $(0.004)$ & $(0.177)^{*}$ \\
\hline \multirow[t]{2}{*}{ Missing father's schooling } & -0.021 & 0.102 & 0.019 & -1.111 \\
\hline & $(0.019)$ & $(1.077)$ & $(0.025)$ & $(1.074)$ \\
\hline \multirow[t]{2}{*}{ Missing mother's schooling } & -0.123 & -6.929 & -0.143 & -3.565 \\
\hline & $(0.025)^{* * *}$ & $(1.416)^{* * *}$ & $(0.034)^{* * *}$ & $(1.469)^{* *}$ \\
\hline Month Indicators & Yes & Yes & Yes & Yes \\
\hline \multirow[t]{2}{*}{ Constant } & 0.415 & 12.181 & 0.464 & 11.631 \\
\hline & $(0.052) * * *$ & $(2.930) * * *$ & $(0.060)^{* * *}$ & $(2.602) * * *$ \\
\hline Observations & 795 & 795 & 690 & 690 \\
\hline R-squared & 0.24 & 0.18 & 0.33 & 0.29 \\
\hline
\end{tabular}

Notes: Standard errors in parentheses are clustered at the household level in each round (* significant at $10 \%$; ** significant at 5\%; *** significant at 1\%). Dependent variable Enrollment indicates whether the child is enrolled in a school during the time of interview and Attendance is the total number of hours the child spent in school during the week prior to interview. Observations for which school attendance was reported to be below normal because of school holidays during the past week are dropped from the sample. 
Table 4a. Impact of ARV Treatment on Schooling (with Child Fixed Effects)

\begin{tabular}{|c|c|c|c|c|c|c|c|c|}
\hline & (1) & $(2)$ & (3) & (4) & $(5)$ & (6) & $(7)$ & $(8)$ \\
\hline \multirow[t]{2}{*}{ Dependent variable: } & \multicolumn{2}{|c|}{ Enrollment } & \multicolumn{6}{|c|}{ Hours of School Attendance in Past Week } \\
\hline & All kids & All kids & All kids & Boys & Girls & All kids & Boys & Girls \\
\hline Hiv hh (no ARVs) * Rd. 2 & $\begin{array}{l}-0.094 \\
(0.102)\end{array}$ & $\begin{array}{l}-0.094 \\
(0.103)\end{array}$ & $\begin{array}{c}1.433 \\
(4.112)\end{array}$ & $\begin{array}{l}-4.162 \\
(6.335)\end{array}$ & $\begin{array}{c}5.371 \\
(4.923)\end{array}$ & $\begin{array}{c}1.587 \\
(4.107)\end{array}$ & $\begin{array}{l}-3.865 \\
(6.287)\end{array}$ & $\begin{array}{c}5.413 \\
(4.974)\end{array}$ \\
\hline ARV hh * Rd. 2 & $\begin{array}{c}-0.004 \\
(0.043)\end{array}$ & & $\begin{array}{c}4.393 \\
(2.664) *\end{array}$ & $\begin{array}{c}6.736 \\
(3.278) * *\end{array}$ & $\begin{array}{c}3.133 \\
(3.559)\end{array}$ & & & \\
\hline ARV hh $(<100$ days $) *$ Rd. 2 & & $\begin{array}{l}-0.005 \\
(0.050)\end{array}$ & & & & $\begin{array}{c}6.665 \\
(3.266)^{* * *}\end{array}$ & $\begin{array}{c}9.140 \\
(4.576)^{* * *}\end{array}$ & $\begin{array}{c}6.360 \\
(3.777)^{*}\end{array}$ \\
\hline ARV hh (>100 days) * Rd. 2 & & $\begin{array}{c}-0.003 \\
(0.055)\end{array}$ & & & & $\begin{array}{c}2.280 \\
(3.038)\end{array}$ & $\begin{array}{c}4.926 \\
(3.317)\end{array}$ & $\begin{array}{c}-0.322 \\
(4.634)\end{array}$ \\
\hline Round 2 & $\begin{array}{c}0.105 \\
(0.056)^{*}\end{array}$ & $\begin{array}{c}0.105 \\
(0.056)^{*}\end{array}$ & $\begin{array}{c}1.712 \\
(3.658)\end{array}$ & $\begin{array}{c}2.588 \\
(5.548)\end{array}$ & $\begin{array}{c}0.844 \\
(4.268)\end{array}$ & $\begin{array}{c}1.501 \\
(3.659)\end{array}$ & $\begin{array}{c}2.212 \\
(5.449)\end{array}$ & $\begin{array}{c}0.802 \\
(4.492)\end{array}$ \\
\hline Month Indicators & Yes & Yes & Yes & Yes & Yes & Yes & Yes & Yes \\
\hline Constant & 0.789 & 0.789 & 25.368 & 25.265 & 25.804 & 25.275 & 25.386 & 25.315 \\
\hline & $(0.073)^{* * *}$ & $(0.073)^{* * *}$ & $(3.809) * * *$ & $(4.735)^{* * *}$ & $5.293)^{* * *}$ & $(3.831)^{* * *}$ & $(4.800)^{* * *}$ & $(5.360)^{* * *}$ \\
\hline Observations & 1532 & 1532 & 1532 & 821 & 711 & 1532 & 821 & 711 \\
\hline R-squared & 0.88 & 0.88 & 0.87 & 0.86 & 0.88 & 0.87 & 0.86 & 0.88 \\
\hline
\end{tabular}


Table 4b. Impact of ARV Treatment on Schooling, by Age and Gender (with Child Fixed Effects)

\begin{tabular}{|c|c|c|c|c|c|c|c|}
\hline & $(1)$ & $(2)$ & $(3)$ & $(5)$ & $(6)$ & $(7)$ & $(8)$ \\
\hline \multirow[t]{2}{*}{ Dependent variable: } & Enroll & Attend & Attend & Enroll & Attend & Enroll & Attend \\
\hline & \multicolumn{2}{|c|}{ Young Boys (8-14) } & Young Girls (8-14) & \multicolumn{2}{|c|}{ Old Boys (14-18) } & \multicolumn{2}{|c|}{ Old Girls (14-18) } \\
\hline HIV hh (no ARVs) * Rd. 2 & $\begin{array}{l}-0.065 \\
(0.119)\end{array}$ & $\begin{array}{c}0.296 \\
(5.269)\end{array}$ & $\begin{array}{c}3.057 \\
(7.659)\end{array}$ & $\begin{array}{l}-0.446 \\
(0.281)\end{array}$ & $\begin{array}{l}-14.660 \\
(8.442)^{*}\end{array}$ & $\begin{array}{l}-0.003 \\
(0.231)\end{array}$ & $\begin{array}{c}7.948 \\
(7.747)\end{array}$ \\
\hline ARV hh (<100 days) * Rd. 2 & $\begin{array}{c}0.043 \\
(0.036)\end{array}$ & $\begin{array}{c}11.392 \\
(5.694)^{* * *}\end{array}$ & $\begin{array}{c}7.974 \\
(6.904)\end{array}$ & $\begin{array}{c}0.017 \\
(0.138)\end{array}$ & $\begin{array}{c}5.191 \\
(5.941)\end{array}$ & $\begin{array}{c}0.011 \\
(0.099)\end{array}$ & $\begin{array}{c}6.347 \\
(4.337)\end{array}$ \\
\hline ARV hh (>100 days) * Rd. 2 & $\begin{array}{c}0.053 \\
(0.043)\end{array}$ & $\begin{array}{c}\mathbf{5 . 3 0 0} \\
(\mathbf{3 . 9 3 3})\end{array}$ & $\begin{array}{c}0.340 \\
(5.660)\end{array}$ & $\begin{array}{c}0.080 \\
(0.147)\end{array}$ & $\begin{array}{c}4.062 \\
(5.006)\end{array}$ & $\begin{array}{l}-0.076 \\
(0.138)\end{array}$ & $\begin{array}{l}-2.005 \\
(6.188)\end{array}$ \\
\hline Round 2 & $\begin{array}{l}-0.007 \\
(0.025)\end{array}$ & $\begin{array}{c}1.785 \\
(6.081)\end{array}$ & $\begin{array}{l}-5.019 \\
(6.971)\end{array}$ & $\begin{array}{c}0.300 \\
(0.151)^{* *}\end{array}$ & $\begin{array}{c}3.206 \\
(7.421)\end{array}$ & $\begin{array}{c}0.084 \\
(0.096)\end{array}$ & $\begin{array}{c}3.010 \\
(4.302)\end{array}$ \\
\hline Month Indicators & Yes & Yes & Yes & Yes & Yes & Yes & Yes \\
\hline Constant & $\begin{array}{c}1.016 \\
(0.042)^{* * *}\end{array}$ & $\begin{array}{c}26.557 \\
(5.716)^{* * *}\end{array}$ & $\begin{array}{c}48.815 \\
(6.920)^{* * *}\end{array}$ & $\begin{array}{c}0.564 \\
(0.206)^{* * *}\end{array}$ & $\begin{array}{c}22.753 \\
(7.628)^{* * *}\end{array}$ & $\begin{array}{c}0.601 \\
(0.100)^{* * *}\end{array}$ & $\begin{array}{c}16.277 \\
(4.725)^{* * *}\end{array}$ \\
\hline Observations & 495 & 495 & 386 & 363 & 363 & 367 & 367 \\
\hline R-squared & 0.77 & 0.87 & 0.86 & 0.88 & 0.89 & 0.89 & 0.90 \\
\hline
\end{tabular}

Notes: Standard errors in parentheses are clustered at the household level in each round (* significant at 10\%; ** significant at 5\%; *** significant at 1\%). All regressions include child fixed effects as well as ten month-of-interview indicators (with one month from each round omitted to avoid collinearity with the round 2 indicator). Dependent variable Enroll indicates whether the child is enrolled in a school during the time of interview and Attend is the total number of hours the child spent in school during the week prior to interview. Young children are defined as children between the ages of 8 and 14 in round 1, old children are defined as children between the ages of 14 and 18 in round 1. Observations for which school attendance was reported to be below normal because of school holidays during the past week are excluded from the sample. 
Table 5. Impact of ARV Treatment on Market Labor Supply (with Child Fixed Effects)

\begin{tabular}{|c|c|c|c|c|c|c|}
\hline & (1) & (2) & (3) & (4) & (5) & $(6)$ \\
\hline Dependent variable: & \multicolumn{6}{|c|}{ Hours worked in past week } \\
\hline Sample: & All 8-18 & Boys & Girls & All 8-18 & Boys & Girls \\
\hline Hiv hh (no ARVs) * Rd. 2 & $\begin{array}{c}-2.168 \\
(2.870)\end{array}$ & $\begin{array}{l}-4.595 \\
(4.642)\end{array}$ & $\begin{array}{c}0.139 \\
(3.653)\end{array}$ & $\begin{array}{l}-2.186 \\
(2.873)\end{array}$ & $\begin{array}{l}-4.614 \\
(4.653)\end{array}$ & $\begin{array}{c}0.150 \\
(3.662)\end{array}$ \\
\hline ARV hh * Rd. 2 & $\begin{array}{c}-4.481 \\
(1.588)^{* * *}\end{array}$ & $\begin{array}{c}-7.721 \\
(2.373)^{* * *}\end{array}$ & $\begin{array}{c}-0.717 \\
(2.178)\end{array}$ & & & \\
\hline ARV hh $(<100$ days $) * \mathbf{R d}$ & & & & $\begin{array}{c}-4.849 \\
(2.016)^{* *}\end{array}$ & $\begin{array}{c}-8.028 \\
(3.133)^{* *}\end{array}$ & $\begin{array}{l}-0.998 \\
(2.712)\end{array}$ \\
\hline ARV hh (>100 days $) * R d$ & & & & $\begin{array}{c}-4.142 \\
(1.958)^{* * *}\end{array}$ & $\begin{array}{c}-7.485 \\
(2.846)^{* * * *}\end{array}$ & $\begin{array}{l}-0.418 \\
(2.775)\end{array}$ \\
\hline Round 2 & $\begin{array}{c}-6.633 \\
(2.760)^{* *}\end{array}$ & $\begin{array}{c}-9.432 \\
(4.115)^{* *}\end{array}$ & $\begin{array}{l}-3.119 \\
(3.799)\end{array}$ & $\begin{array}{c}-6.611 \\
(2.764)^{* *}\end{array}$ & $\begin{array}{c}-9.403 \\
(4.127)^{* *}\end{array}$ & $\begin{array}{l}-3.126 \\
(3.808)\end{array}$ \\
\hline Month Indicators & Yes & Yes & Yes & Yes & Yes & Yes \\
\hline Constant & $\begin{array}{c}18.908 \\
(2.949)^{* * *}\end{array}$ & $\begin{array}{c}24.993 \\
(3.962)^{* * *}\end{array}$ & $\begin{array}{c}9.631 \\
(4.525)^{* *}\end{array}$ & $\begin{array}{c}18.934 \\
(2.953)^{* * *}\end{array}$ & $\begin{array}{c}24.988 \\
(3.970)^{* * *}\end{array}$ & $\begin{array}{c}9.680 \\
(4.544)^{* *}\end{array}$ \\
\hline Observations & 1462 & 788 & 674 & 1462 & 788 & 674 \\
\hline Number of children & 977 & 526 & 451 & 977 & 526 & 451 \\
\hline R-squared & 0.82 & 0.85 & 0.77 & 0.82 & 0.85 & 0.77 \\
\hline
\end{tabular}

Notes: Standard errors in parentheses (* significant at 10\%; ** significant at 5\%; *** significant at 1\%). All regressions include child fixed effects as well as ten month-of-interview indicators (with one month from each round omitted to avoid collinearity with the round 2 indicator). Dependent variable is the total number of hours devoted to income-generating activities in the past week. Observations for which school attendance was reported to be below normal because of school holidays during the past week are excluded from the sample. 
Table 6a. Impact of ARV Treatment on Schooling, All Children in ARV Households Relative to Orphans in Random Sample (with Child Fixed Effects)

\begin{tabular}{|c|c|c|c|c|c|c|c|}
\hline & $(1)$ & $(2)$ & $(3)$ & $(4)$ & $(5)$ & $(6)$ & $(7)$ \\
\hline Dependent variable: & \multicolumn{7}{|c|}{ Hours of School Attendance in Past Week } \\
\hline Sample: & All 8-18 & Boys & Girls & Boys 8-14 & Girls 8-14 & Boys 14-18 & Girls $14-18$ \\
\hline ARV hh $(<100$ days $) *$ Rd. 2 & $\begin{array}{c}10.675 \\
(3.262) * * *\end{array}$ & $\begin{array}{c}15.686 \\
(4.877)^{* * * *}\end{array}$ & $\begin{array}{c}10.805 \\
(4.676)^{* * *}\end{array}$ & $\begin{array}{c}12.356 \\
(6.837)^{*}\end{array}$ & $\begin{array}{c}15.803 \\
(7.443) * *\end{array}$ & $\begin{array}{c}5.074 \\
(8.969)\end{array}$ & $\begin{array}{c}3.381 \\
(7.071)\end{array}$ \\
\hline ARV hh (>100 days) * Rd. 2 & $\begin{array}{c}5.808 \\
(3.133)^{*}\end{array}$ & $\begin{array}{c}10.930 \\
(4.467)^{* *}\end{array}$ & $\begin{array}{c}2.503 \\
(4.566)\end{array}$ & $\begin{array}{c}5.362 \\
(6.557)\end{array}$ & $\begin{array}{c}6.335 \\
(7.041)\end{array}$ & $\begin{array}{c}5.923 \\
(7.635)\end{array}$ & $\begin{array}{l}-6.270 \\
(7.066)\end{array}$ \\
\hline Round 2 & $\begin{array}{c}0.069 \\
(5.665)\end{array}$ & $\begin{array}{c}5.530 \\
(9.624)\end{array}$ & $\begin{array}{l}-5.653 \\
(7.795)\end{array}$ & $\begin{array}{c}18.372 \\
(17.945)\end{array}$ & $\begin{array}{c}-19.897 \\
(6.058) * * *\end{array}$ & $\begin{array}{c}4.539 \\
(13.129)\end{array}$ & $\begin{array}{c}2.513 \\
(10.067)\end{array}$ \\
\hline Month Indicators & Yes & Yes & Yes & Yes & Yes & Yes & Yes \\
\hline Constant & $\begin{array}{c}15.515 \\
(5.872) * * *\end{array}$ & $\begin{array}{c}14.269 \\
(6.991)^{* *}\end{array}$ & $\begin{array}{c}18.733 \\
(10.839)^{*}\end{array}$ & $\begin{array}{c}21.745 \\
(10.168)^{* *}\end{array}$ & $\begin{array}{c}32.879 \\
(8.727) * * *\end{array}$ & $\begin{array}{l}14.451 \\
(9.703)\end{array}$ & $\begin{array}{c}17.158 \\
(12.806)\end{array}$ \\
\hline Observations & 529 & 272 & 257 & 158 & 137 & 130 & 138 \\
\hline R-squared & 0.89 & 0.89 & 0.92 & 0.91 & 0.92 & 0.91 & 0.92 \\
\hline
\end{tabular}


Table 6b. Impact of ARV Treatment on Schooling, Non-Orphans in ARV Households Relative to Orphans in Random Sample (with Child Fixed Effects)

\begin{tabular}{|c|c|c|c|c|c|c|c|}
\hline & (1) & $(2)$ & (3) & (4) & $(5)$ & $(6)$ & $(7)$ \\
\hline Dependent variable: & \multicolumn{7}{|c|}{ Hours of School Attendance in Past Week } \\
\hline Sample: & All 8-18 & Boys & Girls & Boys 8-14 & Girls 8-14 & Boys 14-18 & Girls 14-18 \\
\hline ARV hh (<100 days) * Rd. 2 & $\begin{array}{c}9.460 \\
(4.011)^{* * *}\end{array}$ & $\begin{array}{c}12.121 \\
(7.106)^{*}\end{array}$ & $\begin{array}{c}11.057 \\
(5.135)^{* * *}\end{array}$ & $\begin{array}{c}3.437 \\
(8.565)\end{array}$ & $\begin{array}{c}10.177 \\
(12.086)\end{array}$ & $\begin{array}{c}10.386 \\
(14.999)\end{array}$ & $\begin{array}{c}14.937 \\
(8.096)^{*}\end{array}$ \\
\hline ARV hh (>100 days) * Rd. 2 & $\begin{array}{c}3.274 \\
(4.097)\end{array}$ & $\begin{array}{c}9.457 \\
(7.214)\end{array}$ & $\begin{array}{l}-0.481 \\
(5.629)\end{array}$ & $\begin{array}{c}7.687 \\
(9.364)\end{array}$ & $\begin{array}{c}0.726 \\
(11.355)\end{array}$ & $\begin{array}{c}8.659 \\
(12.990)\end{array}$ & $\begin{array}{c}1.231 \\
(8.947)\end{array}$ \\
\hline Round 2 & $\begin{array}{c}13.782 \\
(10.592)\end{array}$ & $\begin{array}{c}20.469 \\
(19.735)\end{array}$ & $\begin{array}{c}9.952 \\
(12.244)\end{array}$ & $\begin{array}{c}49.563 \\
(20.184)^{* *}\end{array}$ & $\begin{array}{l}-11.198 \\
(21.745)\end{array}$ & $\begin{array}{c}13.170 \\
(15.761)\end{array}$ & $\begin{array}{c}24.773 \\
(15.688)\end{array}$ \\
\hline Month Indicators & Yes & Yes & Yes & Yes & Yes & Yes & Yes \\
\hline Constant & $\begin{array}{c}17.481 \\
(6.462)^{* * *}\end{array}$ & $\begin{array}{l}13.477 \\
(8.650)\end{array}$ & $\begin{array}{c}19.896 \\
(11.283)^{*}\end{array}$ & $\begin{array}{c}14.088 \\
(10.207)\end{array}$ & $\begin{array}{c}38.410 \\
(17.869)^{*}\end{array}$ & $\begin{array}{c}28.891 \\
(17.740)\end{array}$ & $\begin{array}{c}13.103 \\
(11.786)\end{array}$ \\
\hline Observations & 355 & 186 & 169 & 111 & 84 & 85 & 97 \\
\hline R-squared & 0.90 & 0.87 & 0.94 & 0.94 & 0.92 & 0.89 & 0.95 \\
\hline $\begin{array}{l}\text { Notes: Standard errors in pa } \\
\text { regressions include child fixed } \\
\text { omitted to avoid collinearity }\end{array}$ & ntheses (* & gnificant & $10 \% ; * *$ & ignificant & $5 \%$; *** $\mathrm{s}$ & ignificant at & $\begin{array}{l}1 \%) . \quad \text { All } \\
\text { each round }\end{array}$ \\
\hline
\end{tabular}


Table 7. Summary Statistics of Weights and Heights (Round 1)

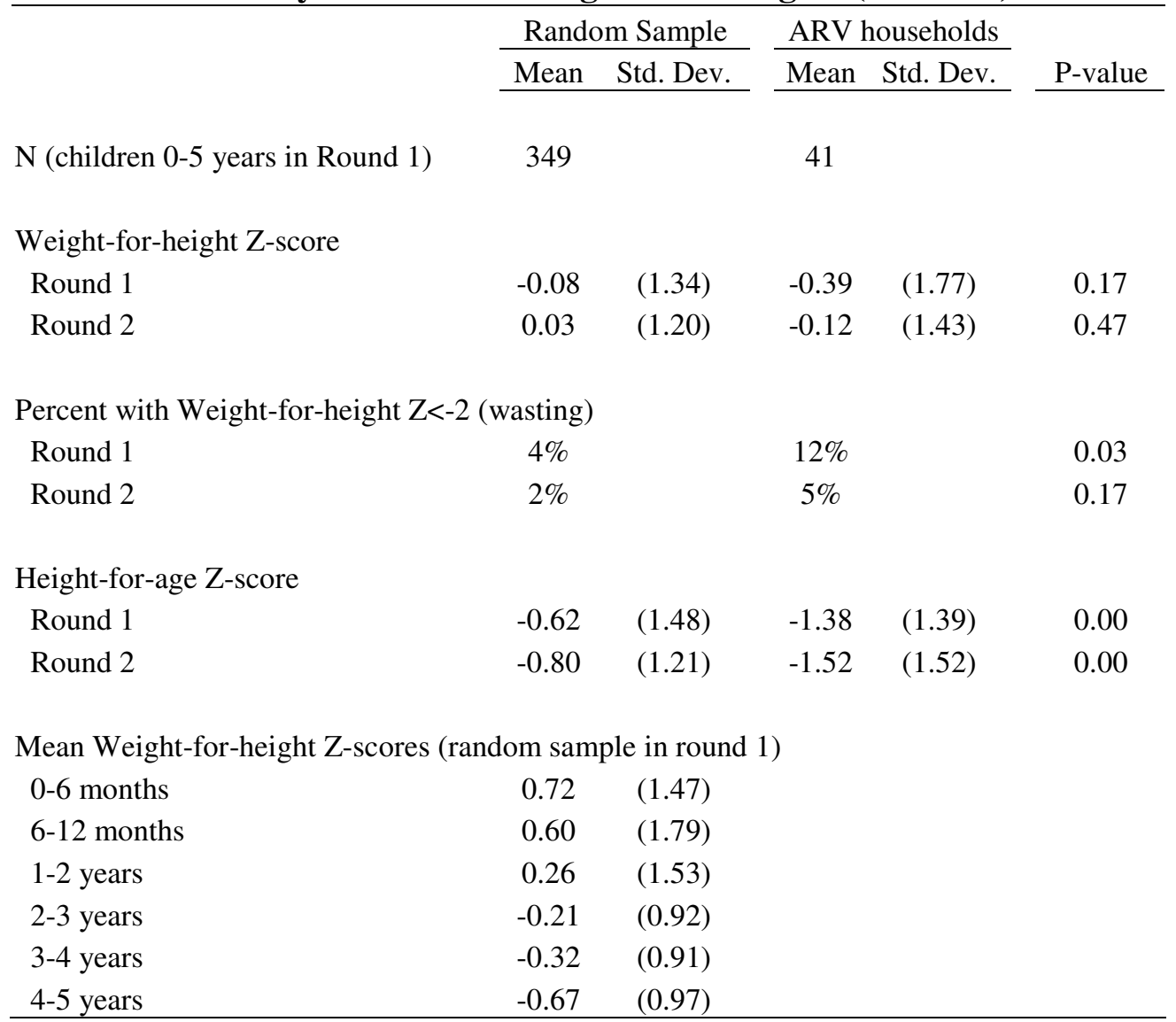

Notes: P-value from t-test for equality of means for children in ARV households and the random sample of households. 
Table 8. Determinants of Weight-for-Height Z-score in Round 1 and 2

\begin{tabular}{|c|c|c|c|c|}
\hline \multirow{3}{*}{ Dependent variable: } & (1) & $(2)$ & (3) & (4) \\
\hline & \multicolumn{4}{|c|}{ Weight-for-Height Z-score } \\
\hline & \multicolumn{2}{|c|}{ Round 1} & \multicolumn{2}{|c|}{ Round 2} \\
\hline Age 6-12 months & $\begin{array}{c}0.096 \\
(0.297)\end{array}$ & $\begin{array}{c}0.074 \\
(0.300)\end{array}$ & & \\
\hline Age $1-2$ years & $\begin{array}{c}-0.503 \\
(0.247)^{* *}\end{array}$ & $\begin{array}{c}-0.506 \\
(0.247)^{* *}\end{array}$ & $\begin{array}{c}-0.794 \\
(0.207)^{* * *}\end{array}$ & $\begin{array}{c}-0.811 \\
(0.206)^{* * *}\end{array}$ \\
\hline Age $2-3$ years & $\begin{array}{c}-0.878 \\
(0.255)^{* * * *}\end{array}$ & $\begin{array}{c}-0.884 \\
(0.256)^{* * *}\end{array}$ & $\begin{array}{c}-1.567 \\
(0.212)^{* * *}\end{array}$ & $\begin{array}{c}-1.567 \\
(0.211)^{* * *}\end{array}$ \\
\hline Age 3-4 years & $\begin{array}{c}-0.949 \\
(0.255)^{* * *}\end{array}$ & $\begin{array}{c}-0.950 \\
(0.255)^{* * *}\end{array}$ & $\begin{array}{c}-1.560 \\
(0.215)^{* * *}\end{array}$ & $\begin{array}{c}-1.574 \\
(0.214)^{* * *}\end{array}$ \\
\hline Age $4-5$ years & $\begin{array}{c}-1.343 \\
(0.244)^{* * *}\end{array}$ & $\begin{array}{c}-1.340 \\
(0.244)^{* * *}\end{array}$ & $\begin{array}{c}-1.674 \\
(0.209) * * *\end{array}$ & $\begin{array}{c}-1.667 \\
(0.209)^{* * *}\end{array}$ \\
\hline Age 5-6 years & $\begin{array}{c}-2.890 \\
(1.419)^{* *}\end{array}$ & $\begin{array}{c}-2.745 \\
(1.446)^{*}\end{array}$ & $\begin{array}{c}-1.990 \\
(0.217)^{* * *}\end{array}$ & $\begin{array}{c}-1.974 \\
(0.216)^{* * *}\end{array}$ \\
\hline Female & $\begin{array}{c}-0.350 \\
(0.135)^{* * *}\end{array}$ & $\begin{array}{c}-0.350 \\
(0.135)^{* * *}\end{array}$ & $\begin{array}{c}-0.227 \\
(0.108) * *\end{array}$ & $\begin{array}{c}-0.224 \\
(0.107)^{* *}\end{array}$ \\
\hline Orphan child & $\begin{array}{l}-0.159 \\
(0.370)\end{array}$ & $\begin{array}{l}-0.190 \\
(0.375)\end{array}$ & $\begin{array}{l}-0.067 \\
(0.285)\end{array}$ & $\begin{array}{l}-0.127 \\
(0.285)\end{array}$ \\
\hline Household variables & & & & \\
\hline with HIV+ patient not on ARVs & $\begin{array}{l}-0.024 \\
(0.309)\end{array}$ & $\begin{array}{l}-0.030 \\
(0.309)\end{array}$ & $\begin{array}{c}0.175 \\
(0.278)\end{array}$ & $\begin{array}{c}0.152 \\
(0.277)\end{array}$ \\
\hline with patient on ARVs & $\begin{array}{c}-0.377 \\
(0.248)\end{array}$ & & $\begin{array}{l}-0.002 \\
(0.203)\end{array}$ & \\
\hline with patient on ARVs $<100$ days & a 1 & $\begin{array}{l}-0.242 \\
(0.355)\end{array}$ & & $\begin{array}{c}0.413 \\
(0.294)\end{array}$ \\
\hline with patient on ARVs $>100$ days & ad 1 & $\begin{array}{l}-0.483 \\
(0.319)\end{array}$ & & $\begin{array}{l}-0.293 \\
(0.252)\end{array}$ \\
\hline Month Indicators & Yes & Yes & Yes & Yes \\
\hline Constant & $\begin{array}{c}0.679 \\
(0.254)^{* * *}\end{array}$ & $\begin{array}{c}0.685 \\
(0.255)^{* * *}\end{array}$ & $\begin{array}{c}1.215 \\
(0.218)^{* * *}\end{array}$ & $\begin{array}{c}1.196 \\
(0.218)^{* * *}\end{array}$ \\
\hline Observations & 404 & 404 & 408 & 408 \\
\hline R-squared & 0.14 & 0.14 & 0.28 & 0.28 \\
\hline
\end{tabular}

Notes: Standard errors in parentheses (* significant at 10\%; ** significant at 5\%; *** significant at $1 \%$ ). Weightfor-Height Z-score is calculated from the measured weights and heights of children and based on comparison to a well-nourished reference population of children in the U.S. All regressions include fixed effects for the interviewer who measured the child. Observations with weight-for-height Z-score or height-for-age Z-score larger than 6 or smaller than -6 are excluded from the analysis. 
Table 9. Impact of ARV Treatment on Weight-for-Height Z-score (with Child Fixed Effects)

\begin{tabular}{|c|c|c|c|c|}
\hline & (1) & $(2)$ & (3) & (4) \\
\hline Dependent variable: & \multicolumn{2}{|c|}{ WHZ } & \multicolumn{2}{|c|}{$\mathrm{WHZ}<=-2$} \\
\hline Sample: & \multicolumn{4}{|c|}{ All children $0-5$ in round 1} \\
\hline ARV household * Round 2 & $\begin{array}{c}0.253 \\
(0.198)\end{array}$ & & $\begin{array}{c}-0.093 \\
(0.041)^{* *}\end{array}$ & \\
\hline ARV households $(<100$ days in $\operatorname{rd} 1) * \operatorname{Rd} 2$ & & $\begin{array}{c}0.570 \\
(0.277)^{* *}\end{array}$ & & $\begin{array}{l}-0.071 \\
(0.058)\end{array}$ \\
\hline ARV households (>100 days in rd 1$) * \operatorname{Rd} 2$ & & $\begin{array}{c}-0.003 \\
(0.252)\end{array}$ & & $\begin{array}{c}-0.111 \\
(0.053)^{* *}\end{array}$ \\
\hline Round 2 & $\begin{array}{l}-0.185 \\
(0.321)\end{array}$ & $\begin{array}{c}-0.166 \\
(0.321)\end{array}$ & $\begin{array}{c}0.018 \\
(0.067)\end{array}$ & $\begin{array}{c}0.019 \\
(0.067)\end{array}$ \\
\hline Age 6-12 months & $\begin{array}{c}0.606 \\
(0.178)^{* * *}\end{array}$ & $\begin{array}{c}0.613 \\
(0.178)^{* * *}\end{array}$ & $\begin{array}{l}-0.055 \\
(0.037)\end{array}$ & $\begin{array}{l}-0.055 \\
(0.037)\end{array}$ \\
\hline Age $1-2$ yrs & $\begin{array}{c}0.460 \\
(0.267)^{*}\end{array}$ & $\begin{array}{c}0.427 \\
(0.267)\end{array}$ & $\begin{array}{l}-0.062 \\
(0.056)\end{array}$ & $\begin{array}{l}-0.064 \\
(0.056)\end{array}$ \\
\hline Age $2-3$ yrs & $\begin{array}{c}0.282 \\
(0.359)\end{array}$ & $\begin{array}{c}0.247 \\
(0.359)\end{array}$ & $\begin{array}{l}-0.028 \\
(0.075)\end{array}$ & $\begin{array}{l}-0.031 \\
(0.075)\end{array}$ \\
\hline Age 3-4 yrs & $\begin{array}{c}0.457 \\
(0.456)\end{array}$ & $\begin{array}{c}0.389 \\
(0.457)\end{array}$ & $\begin{array}{l}-0.032 \\
(0.095)\end{array}$ & $\begin{array}{l}-0.036 \\
(0.095)\end{array}$ \\
\hline Age $4-5$ yrs & $\begin{array}{c}0.376 \\
(0.550)\end{array}$ & $\begin{array}{c}0.291 \\
(0.551)\end{array}$ & $\begin{array}{c}0.039 \\
(0.115)\end{array}$ & $\begin{array}{c}0.033 \\
(0.115)\end{array}$ \\
\hline Age 5-6 yrs & $\begin{array}{c}0.461 \\
(0.631)\end{array}$ & $\begin{array}{c}0.375 \\
(0.632)\end{array}$ & $\begin{array}{c}0.005 \\
(0.132)\end{array}$ & $\begin{array}{l}-0.001 \\
(0.132)\end{array}$ \\
\hline Month Indicators & Yes & Yes & Yes & Yes \\
\hline Constant & $\begin{array}{l}-0.500 \\
(0.385)\end{array}$ & $\begin{array}{l}-0.483 \\
(0.384)\end{array}$ & $\begin{array}{c}0.075 \\
(0.080)\end{array}$ & $\begin{array}{c}0.077 \\
(0.080)\end{array}$ \\
\hline Observations & 812 & 812 & 812 & 812 \\
\hline R-squared & 0.86 & 0.87 & 0.72 & 0.72 \\
\hline
\end{tabular}

Notes: Standard errors in parentheses (* significant at 10\%; ** significant at 5\%; *** significant at $1 \%$ ). Dependent variable $W H Z$ (Weight-for-Height Z-score) is calculated from the measured weights and heights of children and based on comparison to a well-nourished reference population of children in the U.S. In columns 3 and 4 , the dependent variable is an indicator of whether $W H Z$ is less than or equal to -2 (meaning the child is classified as exhibiting wasting). All regressions include child fixed effects, fixed effects for the interviewer who measured the child, and ten month-of-interview indicators (with one month from each round omitted to avoid collinearity with the round 2 indicator). Observations with weight-forheight Z-score or height-for-age Z-score larger than 6 or smaller than -6 are excluded from the analysis. 
Figure 1. Nonparametric regressions of school hours on age, unconditional on enrollment (Random Sample in Round 1)

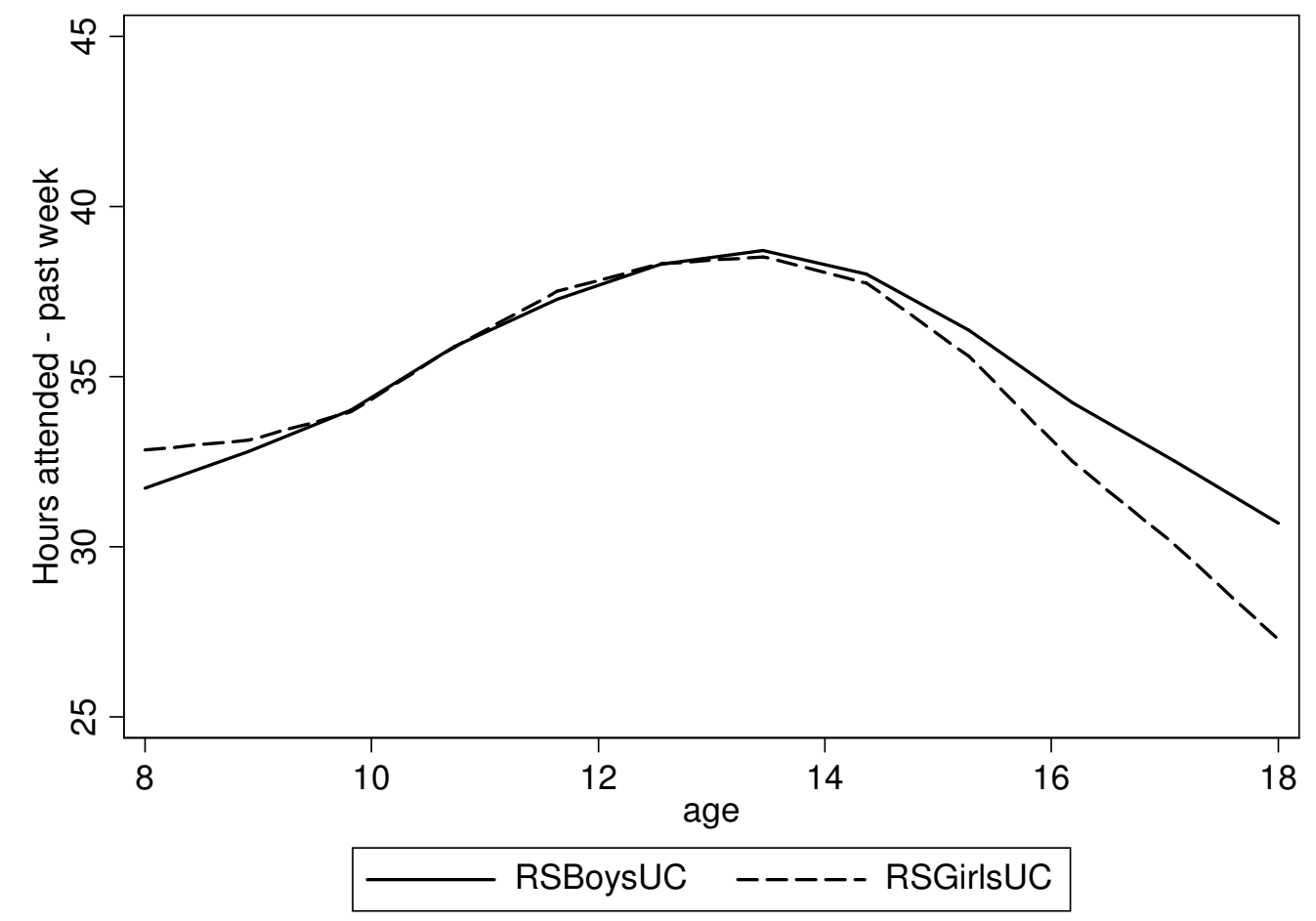

Notes: Figure displays hours of school attended in past week, unconditional on enrollment in school. RSBoysUC and RSGirlsUC refer to boys and girls in the random sample of households, respectively. The nonparametric regressions are estimated using an Epanechnikov kernel, with a bandwidth of 3 hours. 
Figure 2. Nonparametric regressions of school hours on age, conditional on enrollment (Random Sample in Round 1)

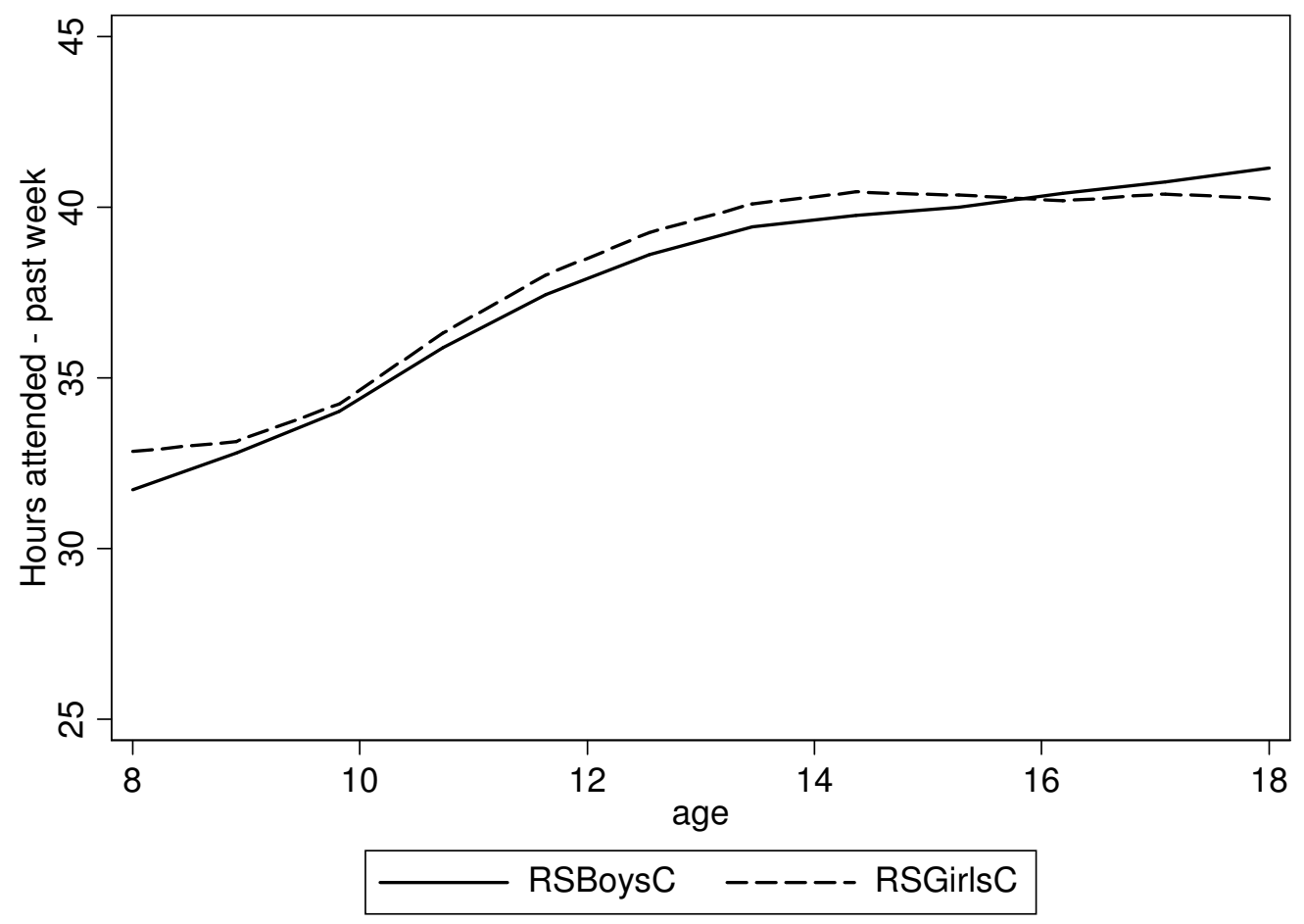

Notes: Figure displays hours of school attended in past week, conditional on enrollment in school. RSBoysC and RSGirlsC refer to boys and girls in the random sample of households, respectively. The nonparametric regressions are estimated using an Epanechnikov kernel, with a bandwidth of 3 hours. 
Figure 3. Nonparametric regressions of school hours on age (Random Sample and ARV Sample in Round 1 and Round 2), unconditional on enrollment

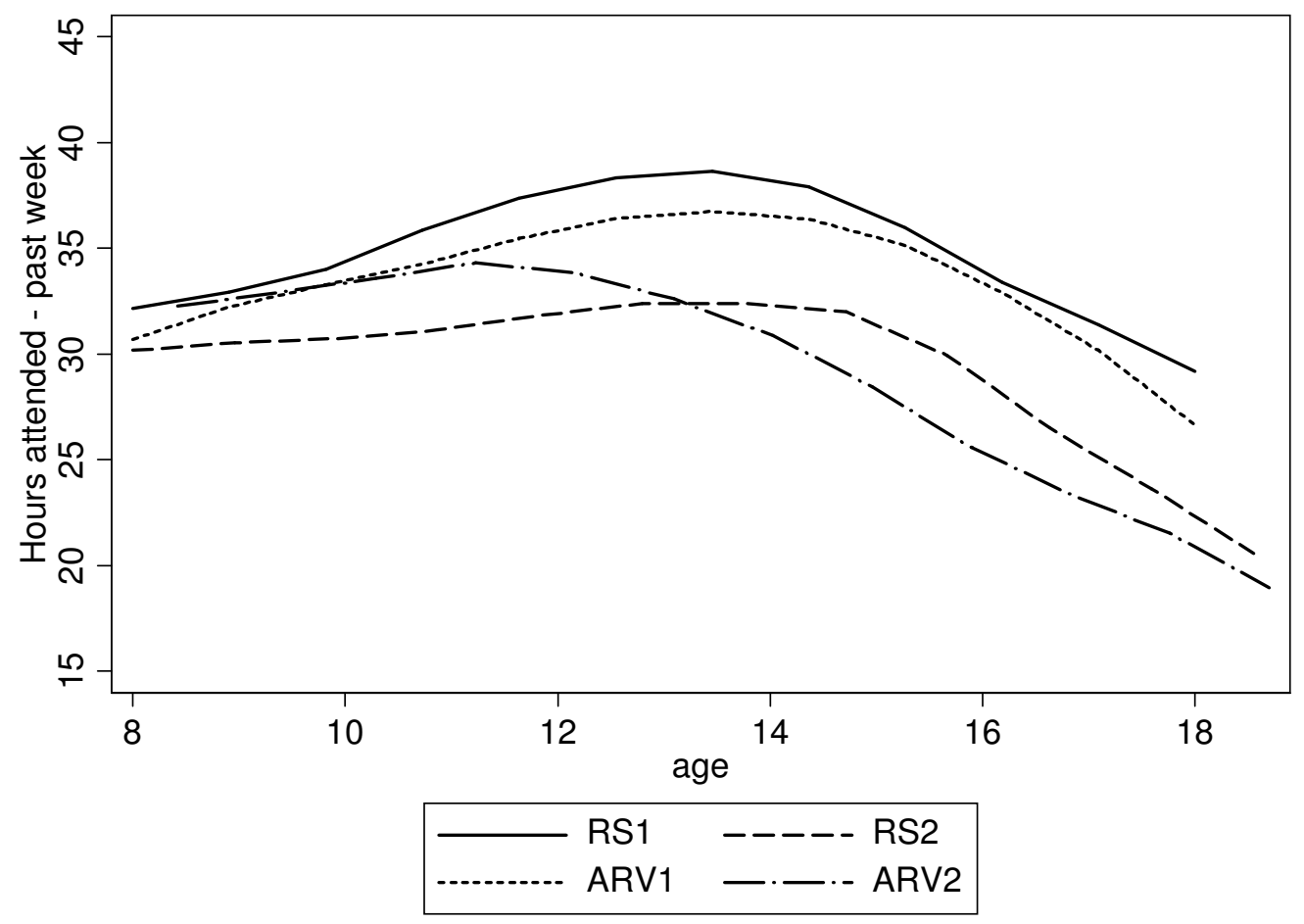

Notes: Figure displays hours of school attended in past week, unconditional on enrollment in school. RS1 and RS2 refer to all children in the random sample of households, in round 1 and round 2 respectively. ARV1 and ARV2 refer to all children in the ARV households, in round 1 and round 2 respectively. The nonparametric regressions are estimated using an Epanechnikov kernel, with a bandwidth of 3 hours. 